Florida International University FIU Digital Commons

$2-1990$

\title{
Transfer of learning between related and less related tasks using content specific and content general learning strategies
}

Ronald W. Collins

Florida International University

DOI: $10.25148 /$ etd.FI14060881

Follow this and additional works at: https:// digitalcommons.fiu.edu/etd

Part of the Adult and Continuing Education Administration Commons

\section{Recommended Citation}

Collins, Ronald W., "Transfer of learning between related and less related tasks using content specific and content general learning strategies" (1990). FIU Electronic Theses and Dissertations. 2409.

https://digitalcommons.fiu.edu/etd/2409 


\begin{abstract}
TRANSFER OF LEARNING BETWEEN RELATED AND LESS RELATED TASKS USING CONTENT SPECIFIC AND CONTENT GENERAL LEARNING STRATEGIES

by

Ronald w. Collins
\end{abstract}

This study compared learning strategies in an effort to determine which strategy would be most beneficial to transfer of learning. A number of approaches were suggested in the related literature for maximizing learning, one of which was to use "learning how to learn," also known by the term content general learning strategy. This study hypothesized that the use of content general learning strategies would produce more transfer of learning across both related and less related tasks than content specific learning strategies. Both learning strategies were combined with either a visual and semantic method of encoding or a semantic only method of encoding. A factorial analysis of covariance (ANCOVA) which combines regression analysis with analysis of variance tested the null hypothesis that the adjusted population means were equal for the covariate of the pretest and the dependent variable of the posttest. Analysis procedures of the ANCOVA on data results reflect that 
for related and less related tasks, content general with visual and semantic encoding outperformed all other methods tested. The results indicate that a general learning strategy (learning how to learn) is more productive for learning achievement in situations where transfer of learning is desired. 
TRANSFER OF LEARNING BETWEEN RELATED AND LESS RELATED TASKS USING CONTENT SPECIFIC AND CONTENT GENERAL LEARNING STRATEGIES

by

Ronald w. Collins

Dissertation submitted to the Faculty of the Graduate School of Florida International University in partial fulfillment of the requirements for the degree of Doctor of Education

1990

Committee in charge:

Dr. Charles Divita, Major Professor

Dr. Barry Greenberg

Dr. Richard M. Hodgetts 
TRANSFER OF LEARNING BETWEEN RELATED AND LESS RELATED TASKS USING CONTENT SPECIFIC AND CONTENT GENERAL LEARNING STRATEGIES

By

Ronald W. Collins

A Dissertation submitted to the college of Education in partial fullfillment of the requirements for the degree

Doctor of Education

Approved by Supervisory Committee:

Major Professor

other Committee Members

February 1990 
TRANSFER OF LEARNING BETWEEN RELATED AND LESS RELATED TASKS USING CONTENT SPECIFIC AND CONTENT GENERAL LEARNING STRATEGIES

by

Ronald W. Collins

A dissertation submitted in partial fulfillment of the requirements for the degree of

DOCTOR OF EDUCATION

in

ADULT EDUCATION AND HUMAN RESOURCE DEVELOPMENT

at

FLORIDA INTERNATIONAL UNIVERSITY

1990 
Copyright c 1990

by

Ronald W. Collins 


\section{ACKNOWLEDGEMENTS}

The author wishes to express his appreciation to a number of individuals to whom he is indebted for their excellent assistance throughout the process of this dissertation. The writer is especially indebted to his graduate committee: Dr. Charles Divita, Jr., Major Professor; Dr. Barry Greenberg; and Dr. Richard M. Hodgetts for their continued patient guidance, constructive criticism and unwavering support during the planning and execution of this study.

Special thanks are expressed to Paula Hertzer, Senior Vice President for Operations of Sun Bank South Florida, N.A., who helped not only in the development of the test instruments but, along with Yolanda Fuentas, Vice President for Operations of Sun Bank, Miami and Martin Smith, Vice President for Security and Training for City National Bank, Miami granted the opportunity to conduct research with their staff of tellers and provided crucial input into this study. Appreciation is due to the many Special Agents of the U. S. Secret Service who contributed input during the construction of the test instruments and lent support during the study. 
Appreciation is also due to Darla Yount, Leslie Hartman, and Qwendolyn Koth for their assistance in setting up the training sessions with the random sample of tellers.

Finally the author wishes to express his sincere appreciation to his mother, Estelle, for her continued support and understanding during this study. 
For my Mother, Estelle 
TABLE OF CONTENTS

Chapters

PAGE

Acknowledgements. . . . . . . . . . . . . . . ii

Dedication. . . . . . . . . . . . . . . .iv

List of Tables. . . . . . . . . . . . . . vii

List of Exhibits. . . . . . . . . . .viii

I. INTRODUCTION. . . . . . . . . . . . . 1

Introduction to the Problem . . . . . . . . 1

Problem Statement... . . . . . . . . . 4

Research Questions and Hypotheses . . . . 5

Purpose of the Study. . . . . . . . . . . . 8

Definition of Terms . . . . . . . . . . . .10

Assumptions . . . . . . . . . . . . . . 12

II. REVIEW OF RELATED LITERATURE. . . . . . . . .14

Introduction. . . . . . . . . . . . . . . . .14

Literature Related to Learning Strategies . .14

Definitions from Related Literature . . . . .20

Studies Focusing on Related Tasks . . . . . .22

Studies Focusing on Less Related Tasks. . . .30

Visual and Semantic versus semantic only

Encoding. . . . . . . . . . . . . . . . . .39

Summary . . . . . . . . . . . . . . .43

III. METHODOLOGY . . . . . . . . . . . . .45

Introduction. . . . . . . . . . . . . .45

Population of the study . . . . . . . . .45

Instructional Intervention. . . . . . . . . .48

Research Design . . . . . . . . . . . . . .49

Analysis of the Data. . . . . . . . . .51

Training Procedures... . . . . . . . . . . . 66

IV. PRESENTATION AND ANALYSIS OF DATA . . . . . .59

Introduction. . . . . . . . . . . . . 59

The Sample. . . . . . . . . . . . . .63

Analysis Procedures . . . . . . . . . .64

Explanation of the Pretest. . . . . . . . .64

Testing the First Null Hypothesis . . . . .66

Testing the Second Null Hypothesis. . . . .72

Testing the Third Null Hypothesis . . . . .75

Testing the Fourth Null Hypothesis. . . . . .77

Testing the Fifth Null Hypothesis..... - Bo

Testing the Sixth Null Hypothesis......81

Testing the Seventh Null Hypothesis . . . 82 
Pretest-posttest Comparison of Independent Variables . . . . . . . . . .84 Introduction to Exhibit 2. . . . . . . . .87 Summary . . . . . . . . . . . . . .89

V. SUMMARY, CONCLUSIONS, RETROSPECT AND

RECOMMENDATIONS . . . . . . . . . . . . . .92

Summary . . . . . . . . . . • . . . . . 92

Conclusions . . . . . . . . . . . . . . . 95

Retrospect. . . . . . . . . . . . . . . .98

Recommendations . . . . . . . . . . . . . 99

VI. LIST OF APPENDIX. . . . . . . . . . 101

APPENDIX A, Demographic Data. . . . . . 102

APPENDIX B, The Pretest . . . . . . . . 103

APPENDIX C, Bank of Questions for the

Posttest on Primary, Related

and Less Related Tasks. . . . 107

APPENDIX D, The Posttest. . . . . . . . . 113

APPENDIX E, Lesson Plan Objectives. . . . 120

APPENDIX F, Projected Pareto Analysis . . . 137

APPENDIX G, Lesson Plans. . . . . . . . 138

APPENDIX H, Job Description Paying and Receiving Teller. . . . . . 149

APPENDIX I, Sample Letters to Banks and

Savings and Loans... . . 154

VII. REFERENCES . . . . . . . . . . . . .156

VITA . . . . . . . . . . . . . . .162 
Comparison of Groups on Pretest Scores by Means, Standard Deviations, F Ratios Significance of $F$.

Comparison of Posttest Means, standard Deviations for the Four Treatment Groups and Two Control Groups Across the Three Measured Items of Primary, Related and Less Related Tasks.

Comparison Between the Treatment Groups of Content Specific and content General Learning Strategies Across the Measured Items on the Posttest of Primary, Related and Less Related Tasks.

Comparison Between Semantic only Encoding and Visual and Semantic Encoding Across the Measured Items of the Primary, Related and Less Tasks.

Comparison of the Sample Population $(\mathrm{N}=300)$ on the Measured Items of Related and Less Related Tasks by Mean, Standard Deviation, Standard Error Reflecting the Mean Difference and the 2 Tailed Probability.

6 Comparison of Independent Variables' Effect on Task Performance by $F$ Ratio and Significance of $F$ from Planned Comparison Procedures.

Comparison of the Independent Variables on the Pretest and the posttest by Means and Standard Deviations. 


\section{LIST OF EXHIBITS.}

Exhibit

Title

Page

1

Treatment Interventions

Comparison of Group Performance Scores by Normalized $\mathrm{T}$-Scores Across the Three Measured Item Tasks of the Posttest 
CHAPTER I

INTRODUCTION

\section{Introduction to the Problem}

Training and education are costly not only to the organizations, groups, and individuals making the financial expenditures, but also to the people involved in the learning act itself. If appropriate strategies are not presented for learners to learn, the learning activity itself could hinder subsequent learning activities and limit potential development of adaptive behavior by the learners, whether they be students or employees (Singer, 1978).

This study dealt with bank teller training in the detection of counterfeit U. S. currency and forged U. S. treasury checks. The study proposed to further both research and knowledge in the area of transfer of learning beyond the parameters of previous studies. The focus of the study was on content specific learning strategies (learning about a specific topic) versus content general learning strategies (learning how to learn) across two methodologies: visual and semantic encoding (actually seeing and handling counterfeit currency) versus semantic only encoding (lecture and minimal visual aid enhancements). 
Recent research into the idea of transfer of learning (Weinstein, 1975; Dansereau, 1978; Mackay, 1982; Logan and Zbrodoff, 1982; Singer and Suwanthada, 1986) has indicated that a solution to the problem of both cost efficient training and the self-actualization of learners (learners reaching their fullest potential) can be found in the use of content general learning strategies. In the literature, content general learning strategies are synonymous with learning how to learn and also learning why something exists, not just how it exists. The term used throughout this study relating to learning how to learn is content general learning strategy. Content specific learning strategies refer only to learning about a specific topic or task with no emphasis on how to learn, (Weinstein 1978; Singer and Suwanthada, 1986). Research indicates that effective strategies can facilitate the acquisition and retention of new information and skills, and "may have the potential to generalize to future-related learning situations," (Singer and Suwanthada, 1986, p. 205).

The following are the four basic areas relating to transfer of learning that were gleaned from the related literature. All of these areas deal in some degree with the learning strategy employed by the learner: 
1. Transference of learning to related tasks having similar cognitive or psycho-motor skill functions.

2. Transference of learning from related tasks to less related tasks or unrelated tasks having dissimilar functions.

3. Semantic only encoding, referring to how information is organized into units for storage into long term memory. Semantic only encoding refers to learning based on lecture/media approach to teaching, where the learner is denied direct access to the object of the study, (Klatzky and Stoy, 1978).

4. Visual and semantic encoding referring to the formation and organization of units of imageful thought or sensory images into long-term memory achieved through actually seeing the physical form of the object or task to be performed, (Kosslyn, 1980; Sternberg, $1985)$.

Learning strategies appear from the review of literature to aid learners significantly in the degree of transfer from one task to another. These strategies, which relate to learning, are associated with the delivery or instructional style used by the trainer during the training session. A number of researchers (Singer \& Peace 1976; weinstein 1975, 1984; Dansereau 1978) have shown support for the concept that 
learning strategies can accentuate cognitive skills for learning specific variables. These same researchers also theorize that metacognitive skills, also known as elaboration skills or learning how to learn, will enable the learner to transfer his or her learning to associated skills related to a similar task (Weinstein, 1975). As Weinstein (1975) reported, the transfer of skills through appropriate learning strategies can be beneficial to both education and industrial training.

In a study relating to closed motor skills transfer, Singer and Suwanthada (1986) showed that groups given content general learning strategies could, on a performance test relating to transfer of learning, outperform other groups given only content specific learning strategies. Their study focused on motor skills and physical properties.

\section{Problem Statement}

In the United States billions of dollars are spent each year on human resource development, yet little concern has been shown for how well the specialized training being taught will transfer to other related skills and tasks that the employee might need to perform. It has been the author's experience in presenting classes to bank tellers and others on the detection of counterfeit currency that little attention 
has been paid by the banking industry, which requests the assistance of the U. S. Secret service in training its tellers, to relating that training to other skills which might benefit from the training. This problem becomes evident when, as an investigator, the author has to interview bank tellers who have been victimized by individuals passing forged U. S. Treasury checks or altered U. S. currency. Occasionally the forgery incident occurs only days after the teller received specific training in detecting counterfeit currency. This indicates a continuing problem for the banking establishments and industry in general with regard to employees being able to generalize or transfer learning. U. S. Treasury Department records reveal more than $\$ 120$ million dollars in only the top 25 circular numbers of counterfeit were passed on the public during the fiscal year 1988. A more generalizable intervention treatment or training method, it is hypothesized, might help the bank tellers to transfer some of their learning to other teller tasks.

\section{Research Questions and Hypotheses}

The basic research question related to transfer of learning is: which learning strategy produces the highest degree of transfer of learning in a given time 
period for instruction, content specific learning strategies or content general learning strategies? To control for the time investment variable a three hour time limit was imposed on all subjects to learn the material.

To further clarify the basic research question, a number of additional questions need to be asked:

1. Is there any difference between content specific learning strategies versus content general learning strategies in the degree of transfer of learning to related and less related tasks?

2. Is there any difference in the degree of transfer of learning achieved using a visual and semantic methodology versus a semantic only methodology?

3. Is there any difference in the degree of transfer of learning on the posttests due to similarity of tasks regardless of strategy or method used?

4. Is there any difference in the demographic and academic characteristics of the population of tellers that effects transfer of learning to related and less related tasks?

These questions formed the basis for the seven null hypotheses to be tested:

1. There is no significant difference between content general learning strategies and content 
specific learning strategies on the degree of transfer of learning to related and less related tasks.

2. There is no significant difference between visual and semantic encoding methods (actually viewing the counterfeit money during training sessions) versus semantic only training methods (lecture/media only) on the degree of transfer of learning which occurs on the posttests.

3. There is no significant difference in the degree of transfer of learning between related tasks and less related tasks regardless of the strategy or method used.

4. There is no significant difference in the posttest item task scores which measure transfer of learning due to the independent variable of level of education.

5. There is no significant difference in the posttest item task scores which measure transfer of learning due to the independent variable of years of experience as a teller.

6. There is no significant difference in the posttest item task scores which measure transfer of learning due to the independent variable of related experiences.

7. There is no significant difference in the posttest item task scores which measure transfer of 
learning due to the independent variable of prior training in the detection of counterfeit currency.

\section{Purpose of the study}

The purpose of this study was to compare content specific learning strategies with content general learning strategies based on the performance of tellers in the transfer of learning on related and less related tasks. The treatment interventions of this study consisting of content specific versus content general learning strategies were studied across two levels of methodology: visual and semantic encoding versus semantic (didactic) only encoding.

Expanding on the study conducted by singer and Suwanthada (1986) which investigated transfer of learning as it related to motor skills, this study focused on cognitive skills of tellers working in a banking environment. This study assessed the relative merit of the two learning strategy treatments across the two levels of methodology.

It is believed that the information gained from this study, if properly used in forming training programs, could save organizations money and maximize learning. If transfer of learning can be achieved, the cost of additional programs of training in highly 
related and less related task assignments could be scheduled to maximize training endeavors.

Banking establishments are but one example of the need for industry to be able to take advantage of transfer of learning (Ehrenberg, 1983). Specifically, in the banking industry, tellers and others who come in contact with the general public need to know not only about the validity of currency but also about the authenticity of other monetary obligations with which they work on a daily basis.

This study, using an empirically-based investigation of transfer of learning in a banking situation, was able to address the research questions and provide information for all human resource development programs on techniques for maximizing transfer of learning.

As Craig (1966) stated when discussing the possibility of transfer of learning, "any condition of readiness, motivation, exploration and learner activity, or consequence of that activity, that improves learning and retention, also increases the possibility for transfer of learning" (p.156). The results from a number of conflicting studies have confounded the basic issue relating to transfer of learning. Further empirical studies are needed to increase awareness of the importance of transfer of 
learning as a legitimate end to be sought in instructional design for educational and business communities. Bruner (1960) stated: "The first object of any act of learning, over and beyond the pleasure it may give, is that it should serve us in the future" (p.247)

As explained in the following chapter, research on the transfer of learning has gone through several stages since its early foundations (Thorndike, 1913; Coxe, 1924; Rapp, 1945; Craig, 1953; Ellis, 1965; Haslerud, 1972: Gagne", 1974; Weinstein, 1975, 1984, 1987). It was the purpose of this study: (1) to contribute to and clarify the results of transfer of learning by adding to the body of knowledge relating to learning strategies which can promote transfer of learning and (2) to distinguish if content specific learning was more beneficial to industrial needs than content general learning.

\section{Definition of Terms}

Extensive studies in the area of transfer of learning have given rise to ambiguous nomenclature, as each researcher tends to develop his or her own terminology to describe a phenomenon. This section attempts to clarify terminology previously used, as well as to introduce new terms related to this specific 
study. Additional terms are defined within the Review of Literature chapter.

1. Learning strategy - includes any thoughts or behaviors that help learners acquire new information and integrate that information into an existing base of knowledge (Weinstein, 1975).

2. Learning style - the individualized approach to reception or acquiring of new information. A learning style can be learned or innate (Dansereau, 1978).

3. Metacognition - The ability to be reflective on one's own thinking or cognitive processes as well as the ability to reflect on the style of learning (Weaver, 1987).

4. Negative transfer - refers to situations where prior learning interferes with new learning, especially if the new response is incompatible with the old response (Ellis, 1972).

5. Positive transfer - refers to situations where prior learning facilitates or aids subsequent performance (Ellis, 1972).

6. Semantic encoding - Learning based on lecture/media approach to teaching, where the learner is denied direct access to the object of study but where the object is described fully in lecture and/or via some media vehicle (Klatzky and Stoy, 1978). 
7. Visual encoding - The formation and organization of units of imageful thought or sensory images into long-term memory achieved through actually seeing the physical form of the object or task to be performed (Sternberg, 1985; Kosslyn, 1980).

8. Zero transfer - refers to a situation where no effect can be measured from prior learning on new learning (Ellis, 1972).

9. Transfer of training - synonymous with generalizability of training, transfer of skills, and transfer of learning. This can include both positive transfer or negative transfer. 10. Related tasks - those tasks having similarity of cognitive procedures or skills using similar motor movements (Singer and Suwanthada, 1986). 11. Less related tasks - tasks or skills requiring different cognitive structuring or motormovement (Singer and Suwanthada, 1986).

\section{Assumptions}

Assumptions of the study were as follows:

1. All mentally and physiologically healthy individuals transfer learning as a normal cognitive procedure (Haslerud, 1972). 
2. Learning changes discriminability (perceived distinction or quality) of information (Thorndike, 1913, cited in Haslerud, 1972).

3. Transference is an automatic occurrence of sensory features triggered by the input signal of active stimuli (Haslerud, 1972).

4. Fluency and flexibility in the cognitive process increase the proportion of comprehensive transference (E11is, 1972).

5. Transference of either positive or negative typology can be quantifiably measured and evaluated by degrees of learner performance (Gagne', 1974).

6. The cognitive processes involving receiving, coding, retrieval and projection-anticipation must be engaged before transference can be established (Goldstein and Blackman, 1978). 
CHAPTER II

REVIEW OF RELATED LITERATURE

\section{Introduction}

This chapter reviews appropriate theory and research on the transfer of learning. It is organized into six sections. The first section provides a brief background of transfer of learning and the use of learning strategies. The second section presents definitions from related studies of transfer of learning. The third section discusses a number of related studies focusing on transfer of learning from one task to a related task. The fourth section is devoted to a review and discussion of a number of related studies focusing on transfer of learning from a related task to a less related task. The fifth section presents pertinent research directed at the differences between visual and semantic encoding and semantic only encoding. The sixth section summarizes the main points investigated in the first five sections.

\section{Literature Related to Learning strategies}

In the literature, the term transfer of learning is often used interchangeably with generalizability of training and transfer of training. An early definition 
articulated by English and English (1958) stated that transfer was a term for "change in ability to perform a given act as a direct consequence of having performed another act relevant or related to it" (cited in Haslerud, 1972). A more recent definition postulated by Gelzheiser, Shepherd and Wozniak (1986) is that generalization is one of the basic and essential criteria used to evaluate learning. Generalization, in this case, refers to the process in which an activity or response extends adaptability from similar to highly differentiated environments (Singer and Pease, 1976).

As Weaver (1987) suggests, transfer of learning is a subject that has not lacked in research studies, yet it has a number of "questions that seem to persist unanswered through several generations of research" (p. 582$)$.

Transfer of learning was hypothesized by both E. L. Thorndike and Charles H. Judd as early as 1908 . Thorndike reflecting on transfer of learning, advised that even small degrees of learning may be of great educational value if that learning was extended over a wider field (Haslerud, 1972). "If a hundred hours of training on being scientific about chemistry produced only one-hundredth as much improvement in being scientific about all sorts of facts, it would yet be a 
very remunerative educational force." (Thorndike, 1913, cited in Haslerud, 1972).

According to Weaver (1987), "Thorndike argued that transfer is based on identical elements across tasks, while Judd maintained that transfer grows out of the ability to generalize knowledge across different situations." Neither view has been resolved to be untenable. According to Haslerud (1972) the Thorndikian transfer paradigm refers to "transfer by response generalization." Yet, Haslerud (1972) argued that Thorndike felt transfer was the overlap of identical elements from old to new situations.

Thorndike's "connectionist" or "S-R " theory of learning, evolved into the cognitivist approach which espoused the "S-O-R" theory or "stimulus organism response" theory of learning. Another view of transfer of learning can be seen in the work of Jean Piaget, one of the most influential of the cognitive theorists. Although focused primarily on children, Piaget's work in the realm of transfer of learning is also important in the area of adult learning. Piaget identified, at least tentatively, "significant changes in cognitive capacities, processes, and phenomena as a function of age, experience, and intellectual sophistication" (Anderson and Ausubel, 1965). According to orthodox views of Piaget's theory, logical concepts based upon 
the same operational structure should demonstrate "synchronous developmental patterns" or "logical groupments of concrete operations" (Hooper, 1979) . A slightly different concept is offered by Ausubel (1972) who approaches transfer of learning from the cognitive structure. This, he points out, consists of more or less organized and stable concepts or ideas embedded in memory. Ausubel introduced the term of "subsumer" to define a concept or idea which includes other ideas and concepts. Subsumption occurs when meaningful material is incorporated into the cognitive structure. Learning and transfer of learning occurs when incoming material is linked to preexisting structure and becomes an extension of that previous knowledge.

Dansereau (1978) advised that, for too long the design of education has ignored the importance of transfer of learning. He explained, "educational research and development efforts have been directed almost exclusively at the improvement of teaching. The relative neglect of the learning aspect of education is probably unwarranted, especially when one considers the importance of ameliorating the transfer of classroom knowledge and skills to the job situation" (p. 1). As important as tranfer of learning maybe, however, weaver (1987, p.584) points out, "if we are undecided about the nature of transfer, how can we state with any 
degree of certainty that transfer has occurred?" She questioned measurement processes and evaluation to analyze if transfer had taken place and how to measure the degree of its occurrence. She also questioned if principles of transfer should be incorporated into teaching plans if uncertainty exists regarding the basis from which such principles should be derived. H. C. Ellis (1965) advised that "transfer of skill is a practical issue for education and a fundamental issue for psychology, but, though a number of studies have been conducted, little is known about why transfer either occurs or fails to occur." In a subsequent work, Ellis (1972) defines "transfer of training" as referring to the influence of prior learning on performance in some new situation. He pointed out that transfer effects could be positive, negative, or zero, if no effect was observed. He reported that there were several kinds of transfer theories available. Transfer of learning is seen as being on a continuum ranging from theories based upon the principle of generalization of stimulus-response association to cognitive theories of transfer. Transfer of tasks learning is ever-present throughout educational processes, but the range of research directed at its investigation has been sporadic and without planned and guided direction. 
Goldstein and Blackman (1978) advise that transfer of learning is a component of the cognitive processes of the individuals and that "cognition is a mediating process between the stimulus and response." In this respect they advise that the more cognitively complex the individual, the more likely the individual will integrate discrepant information and transfer it to related stimuli.

Ellis (1965) postulated that problem-solving, the thinking dimension of cognitive processes, functions best when the learning is meaningful or familiar material. Judd (1932) advised that "the nature of generalization is such that no simple formula like that of the presence of identical elements is remotely adequate. Generalization is a type of organized mental reaction; it depends on creative synthesis" (p. 227).

As Ellis (1972), points out, "the assumption of transfer underlies much of what is taught in the classroom. Obviously, there must be some transfer or every new learning situation would involve starting from scratch... Therefore, the issue is not if transfer occurs, but rather the 'conditions' under which transfer occurs" (p.247).

In summary, the study of transfer of learning, also known as generalizability of training or transfer of training, is an essential component of the study of 
education in general and the learning process specifically.

\section{Definitions from Related Literature}

All scientific theory, according to Hull (1937), "should begin with a set of explicitly stated postulates accompanied by specific or operational definitions." This section presents the formal structure of the theory as developed in the form of assumptions to date as well as a list of definitions for the terminology used throughout this study. The history of transfer of learning or generalizability of training has seen a number of developments. Craig (1966) pointed out that all education aims for a carryover from one level to another or from school to life. Neisser (1969) provided support to the view that memory is not a "static depository but a dynamic, reconstructing behavior." Weinstein (1975) showed that learning strategies or "elaboration strategies are a concept of the cognitively active learner." Capione and Brown (1977) showed that there was a differentiating effect between maintenance and generalization of a learned strategy. Singer $(1979 ; 1986)$ provided evidence of the transferability of learned motor skills to related motor skills as part of the cognitive process. 
The definitions from related literature pertaining to this study are as follows:

1. Attention - a momentary concentration of need for information accompanied by reduction of the threshold for a narrow span of stimuli (Thorndike, 1913).

2. Cognition - a mediating process, part of that aspect of the perceptual-cognitive processes, of thinking, dreaming, consciousness, which emphasizes the intensity or level of activity in which the organism is engaged (Haslerud, 1972).

3. Cognitive style - a hypothetical construct developed to explain the process of mediation between stimulus and response. Refers to characteristic ways in which an organism conceptually organizes the environment (Goldstein and Blackman, 1978).

4. Content dependent learning strategy - Where learners concentrate solely on the task to be performed and not how the task relates to other tasks. It is learning how to perform an individual task (singer and Suwanthada, 1986).

5. Content independent learning strategy - where the learner is concerned with learning how to learn. Learner is goal-directed, reflective, and knowledgeable about cognitive processes and how to control those processes (Singer and Suwanthada, 1986). 
6. Fluency - a measurement of the number of concepts, ideas, or solutions produced in a given unit of time (Gagne', 1974).

7. Flexibility - the ability of the organism to access different portions of the knowledge base, measured in number of types of responses produced (Haslerud, 1972). 8. Generalizability - the process in which an activity or response extends adaptability from similar to highly differentiated environments (Singer and Pease, 1976).

9. Global learning strategy - synonymous with content independent learning strategy. Use of metacognitive processes (Singer and Suwanthada, 1986).

10. Response learning - the process by which the responses become integrated so that they are available for recall (Ellis, 1972).

The next several sections of this chapter will look at studies which focused on transfer of learning from a task to a related task and from a task to a less related task.

\section{Studies Focusing on Related Tasks}

This section looks at studies which focused on the transfer of learning from a primary task to a related task.

Singer and Pease (1976) devised a study which investigated the relationship of transfer of learning 
over three variables: a guided instructional strategy; a discovery instructional strategy; and a combination discovery-guided strategy. The guided instructional method used instructor prompts to enhance learning while the discovery learning method consisted of mainly trial and error problem solving exercises. The study incorporated a number of the discovery learning assumptions of Bruner (1960). Their efforts were to compare the effects on initial task learning and retention by transfer to a second related task. The tasks were motor skills derived from utilization of a computer-managed novel serial manipulation apparatus containing eight hand and four foot manipulated objects. It was Singer and Peace's (1976) contention that the literature supported the hypothesis that guided techniques of learning are the most efficient. Singer and Pease (1976) cited a number of studies (Craig, 1956; Kersh, 1962; Prather, 1970) which reflected that increased motivation among discovery learning groups was a critical factor in promoting transfer of learning and that trial and error learning was generally more efficient in obtaining transfer than error-free learning.

The subjects for their study consisted of forty-eight undergraduate college students who volunteered for the study. The results found a 
significant difference between the conditions they had established, namely combinations of tasks required transfer of learning from task to task within a given time period $(F=8.35, \mathrm{df}=2.41, \mathrm{p}<.01)$. They advised that the transfer analysis reflected significant differences between blocks (blocks are the groupings of trials associated with initial learning reported on the ANOVA) and conditions (conditions are the types of instruction) when multiplied times blocks. The evidence of the occurrence of transfer was shown, according to singer and Pease, (1976) through an analysis of the first block of scores on each of the two tasks for the discovery group.

The findings revealed that a guided and prompted method of learning is the most efficient when considered from a learning-time factor (the amount of time it takes to learn an item) for the purpose of initial learning. They also found that once the initial task was learned, the learning of a related task could be enhanced if the initial learning involved a learning strategy that required some sort of problem solving.

Seong-Soo Lee (1985) also conducted a study focusing on the generalizability of training to a second related task. His study investigated the teachability of conditional logic structure using a 
transfer of training paradigm. Lee (1985) advised that the component process analysis of "syllogistic conditional reasoning task" involves three main components. The first component he described as the "inductive rule," or learning-attribute coding and rule mapping. The second component was the induction of conditional language. The third component was the "deductive interpretation" which Lee described as "decoding, matching, and evaluation." The study attempted to use the same subjects during both trial periods to gain a longitudinal effect. The subjects were introduced to a conditional structure to see if they could transfer the learning to the deductive interpretation of "if-then" statements in a normative conditional format.

The design of the research was to study transfer of learning from one task to a related task. The pretest and posttest each consisted of a total of forty syllogism items for deductive interpretation. Forty items resulted from the factorial combination of five semantic types times eight item types. A criterion was established that set $80 \%$ or 32 out of the 40 items to reflect a mastery of the structure. Lee (1985) explained the criterion used as a "statistical consistency of responses over replicated items and internal congruence of responses according to the 
normative conditional interpretation." Accordingly, he advised that the "expected chance score out of a maximum of 40 questions for any individual learner is 13.33" (Lee, 1985, p.19).

Tennyson, Chao and Youngers (1981) focused on related task transfer of learning in their study. They researched the hypothesis that concept learning was a two-fold process which included both acquisition of a prototype and development of generalization and discrimination skills. Their research reflected that learning and generalization of learning to related tasks was facilitated through the use of what they referred to as, "presentation form" which was a combination of expository statements of "best examples" of skill development (defined as prototype acquisition with interrogatives) over presentations that were expository or interrogatory only. According to these researchers, learning concepts require the acquisition of generalization and discrimination skills. The development of such skills was found to be most easily facilitated when concept examples ranging from easy to difficult were matched to nonexamples on the basis of similarity of variable attributes and the divergence in variable attributes was noted. The design which was used had three methods: expository, interrogatory and a combination of expository-interrogatory. They 
hypothesized that the expository-interrogatory presentation form would more readily facilitate both initial formal learning and retention ( 1 week later) to a greater extent than would the expository or interrogatory presentation forms by themselves.

The study employed a two-way factorial design with six treatment conditions. The results were analyzed using a multivariate analyses of variance and univariate tests on each dependent variable followed by a mean comparison test (Student-Newman-Keuls). According to Tennyson, Chao and Youngers (1981), the multivariate dependent variables consisted of the posttest correct scores on the four levels of concept attainment.

The results of their investigation supported their research hypothesis about concept learning involving development of prototype acquisition and the need for generalization (transfer) and discrimination skills. The data reflected that generalization of skills was learned by subjects who were presented with an expository-interrogatory format "which allowed matching of their prototype with newly encountered examples and nonexamples," (p. 333).

A number of studies have focused on the need to induce skill transfer (Singer and Pease, 1976; Rogoff and Gauvain, 1984; Gagne", 1984, Clements, 1984; 
Gelzheiser, Shepherd, and Wozniak, 1986; et al). Transfer, as Haslerud (1972) advised, is the key to learning, retention, and the ability to adjust to an ever-changing environment. Transfer of learning allows the participant the freedom to be fluid instead of fixed or held in check because one has not been specifically taught about a task or topic. According to Flavell (1976) regarding the metacognitive aspects of problem solving, the more a subject knows proper methods and styles of thinking about thinking, the better functioning of their own cognitive processes will follow.

A study concerned with transfer of learning (or generalization) as a criterion used to evaluate learning and instruction was conducted by Gelzheiser, Shepherd, and Wozniak, (1986). Their study centered on a group of learning disabled subjects $(N=42)$. The hypothesis of the study was that learning of self-regulatory skills of organization would reflect a significant difference in transfer of learning over no organized learning. The results of the study reflected that the fewer new rules subjects had to learn the better they were able to attain proficiency and to generalize to a different rule. They also found, as Ellis (1972) and Duncan (1958) previously reported, 
that the rate of transfer is directly related to the similarity of the tasks.

Duncan (1958) had already shown that the use of learning to learn and "learning sets" clearly improves performance during practice on a series of similar tasks. Ellis (1972) detailed how individuals could improve their proficiency in ability to learn new tasks and skills as a result of prior practice on a series of related tasks. It is this ability to transfer general modes of learning or adoption of appropriate learning sets to new situations that Ellis (1972) emphasizes is the basis for learning to learn, which is the basis of transfer of learning.

In summary, this section has reviewed pertinent studies focusing on transfer of learning from a primary task to a related task. The general consensus from these studies reflects the view that learning how to learn is more beneficial to transfer of learning than specific content learning. Also reflected from the studies included in this section is the view that there is a significant difference in the use of organized learning material over no organization.

In the next group of studies, the emphasis is on how transfer of learning from a primary task transfers to a similar or related task and also to a less related task. 
Studies Focusing on Less Related Tasks

A number of studies have been conducted to measure the degree of transfer of learning from a primary task to a less related task. Several of these studies use both similar and dissimilar tasks when testing the quantity of transference achieved.

Rogoff and Gauvain (1984), using a multiple regression procedure, studied the effects of transfer of cognitive skills across several "domains" through comparison of weaving of cloth skill to "formal schooling" (actually attending classes) on the effectiveness of performance in completing a number of pattern continuation tests. From the tests, the subjects were compared on their similarity across the variables of weaving and schooling. The study was interested in comparing the predictiveness of the two types of learning, classroom schooling versus an everyday learning skill such as weaving. Rogoff and Gauvain (1984) postulated that there were widely held assumptions that cognitive skills observed in a small number of situations were representative of more pervasive abilities or characteristics of the individuals across different situations or "domains." They took exception to what they refer to as psychologists who "neutralize the task so that 
performance reflects pure process" while assuming that a human's capacity characterizes the individual's thinking across a large number of tasks (Rogoff and Gauvain, 1984, p.454). They argued that it is not so much the similarity of the task as the task function situation that should be varied. From this, they hypothesized that possibly the "cognitive skill was not an abstract, context-free competence that could be easily transferred across widely diverse problem domains." (p.454). There was a possibility that there was a specificity factor, with certain skills tied to particular types of cognitive activity.

Rogoff and Gauvain (1984) as well as a number of other theorists (Duncan, 1958; Ellis, 1972; Singer and Pease, 1976) point out that transfer of skills to related tasks are occurrences that everyone participates in everyday. Individuals would be extremely limited if they could only apply learned material to identical problems which were performed repeatedly. As Ellis (1972) has advised, individuals must actively seek analogies across problems to guide them in finding similarities. It was Rogoff and Gauvain's (1984) contention that only by studying a less related or unrelated task transference of skill can accurate evaluations be made on the transfer of learning. Rogoff and Gauvain (1984) pointed out that 
formal schooling was viewed as the one experience in Iife that provided a general learning set or "learning to learn" ability where people were taught the ability to transfer skills and information to new situations. It was for that reason, they cautioned, that school skills may not transfer any more broadly than nonschool skills.

To test their hypothesis, Rogoff and Gauvain (1984) selected seventy-nine Navajo women varying in expertise in weaving and in amount of formal schooling. The amount of schooling was found to be related to the individual's age, the younger the individual the more schooling they had acquired, while the expertise in weaving was found to be greater among the older women, thus the two variables were negatively related to one another. As cross (1981) points out, the level of education per cohort age groupings will remain a constant. The older a person is, the more the probability that they will not have had very much schooling.

The results of the Rogoff and Gauvain (1984) study revealed that schooling did not have a predictive quality more effective than weaving experience either in the weaving construction task or in the formal school formatted tasks. (The subject's age was highly predictive on the formal school formatted task). They 
concluded that formal schooling did not promote learning how to transfer skills from one problem to another any better than work experience. In fact, they advise that weaving experience fared better in transferring skills to unrelated tasks.

Mackay (1982) also studied transfer of learning to related and less related tasks by focusing on how individuals become more fluent in high-proficiency skills. He offered an explanation regarding the relationship between two seemingly unrelated variables. The first variable dealt with fluency. Task fluency, (faster, less prone to error) according to Mackay (1982), relates to the behavior sequences and their relationship to practice. He also focused on higher degrees of fluency associated with greater "automaticity" (reduced effort and conscious awareness). The second variable dealt with the question of flexibility; how individuals transfer skill acquired in practicing one performance to a second less related task and how they adapt or substitute components of an ongoing behavior sequence during the execution of the act itself.

Mackay (1982) theorized that his study showed the transfer process from one response mechanism to another and why individuals can achieve almost perfect transfer from one hand to the other for simple skills, (e.g. 
moving a chess piece) as well as higher cognitive transfer of behavioral sequences. Mackay (1982) defined the nodes he referred to as the basic "components for organizing complex actions" which he advised were divided into at least "two independently controllable systems: a mental and a muscle movement system" (p.500). Nodes within the muscle movement system represent "muscle-specific patterns of movement" while mental nodes represent classes of actions and are "part of a syntactic domain" (Mackay, 1982, p. 500).

This study concluded that transfer of learning involves both "one to many connections (of nodes) which represent the set of possible transfer alternatives and many to one connections (that determine which of these transfer alternatives becomes activated in any given context)" (Mackay, 1982, p. 502).

Singer and Cauraugh, (1985) focused on the transfer of learning in the generalizability effect of learning strategies for differing categories of psychomotor skills. They postulated that there was a need for recognition of the cognitive processes and learning strategies used for achieving psychomotor tasks. It was their contention that all too often there was a general disregard for these variables in the design of instructional programs involving the mastery of specific content. 
Singer and Cauraugh (1985) contend that strategies which support learning performance should be classified into two main categories: primary and secondary. They define primary strategies as those related to achievement in skills. Gagne' and Briggs (1974) have referred to primary strategies as "associative strategies." The second category or "secondary strategies," referred to by Dansereau (1978) as "support strategies," assist and facilitate the effective operation of primary strategies. These strategies, according to singer and Cauraugh (1985), "reflect potential cognitive control over performance and feelings."

Singer and Cauraugh (1985) categorize motor skills as either closed or open; that is, the motor skills are either self-paced or externally paced. By the term "closed tasks," they refer to those initiated when the learner is ready, while the "open tasks" were those that required appropriate responses in what they termed "dynamic situations." The definition of dynamic situations was ambiguous but related to individuals adapting to unpredictable events with rapid performance. These strategies were activated, according singer and Cauraugh (1985), through a self-initiated or externally imposed way of directing information leading to decisions for purposeful 
behavior. In this way the learner "imposes some type of structure on movement of information so that it is learned and retrieved more efficiently" (Singer and Cauraugh, 1985, p. 106). Yet, if transfer is to be achieved without the aid of an instructor's presence, the learner needs to become capable of self-generating strategies, whether externally directed or self-generated.

Singer and Cauraugh (1985) point out that transfer of cognitive skills depends upon the similarity between the test situation and the acquisition strategy. Differences between these two variables will affect performance outcome. In the case of motor skills, though transfer of skills from task to task may be "situation specific," the strategy of transfer for those situations is somewhat generalizable.

Chen (1984) focused on the importance of related task transfer of skills and learning in elementary physics. To accomplish this, he selected both similar and dissimilar tasks to analyze transfer of learning. His study attempted to determine the effects of including supplementary readings designed to help students relate physics to other fields of study, with the study of physics. The college students $(n=233)$, were measured for both achievement and attitude changes in their performance. Significant improvement 
differences were found as students began to learn how to apply and transfer their readings in physics to other subject matter.

A key study which focused on the problem of transfer of learning between related and unrelated tasks was undertaken by singer and Suwanthada (1986). In this study, which looked at the generalizability effectiveness of a learning strategy on achievement in related closed motor skills, an attempt was made to determine the effectiveness of a "global learning strategy on the skill level attained in one closed primary task and two related ones." They advised that transference of related tasks was measured with one task using similar motorskills and the other task using different motorskills or less related skills.

Singer and Suwanthada (1986) hypothesized that learners would be more effective if they learned how to learn, and any acquisition of metacognitions would facilitate the process. It was their belief that metacognitions, which they defined as strategies to facilitate learning, would aid in the generalization process. It was also hypothesized by singer and Suwanthada (1986) that "a task-relevant comprehensive learning strategy" would enhance achievement in all tasks if it was compared to a condition in which the strategy was not introduced. The major purpose of 
their study was to determine the effectiveness of a general learning strategy on the transferability from a primary task to a "closely-related task," and a "slightly-related task."

A secondary purpose for their study concentrated on the context in which "the strategy could be taught." It was their contention to ascertain the relative effectiveness of a "strategy content-dependent learning situation versus a content-independent situation."

Singer and Suwanthada (1986) hypothesized that "the content-dependent strategy" would be most beneficial in the learning of the primary task, as the frame of reference for the subjects was to learn a specific task. In direct contrast to this was the content-independent strategy which was expected to benefit the learning of related and less related tasks.

Their results appear to confirm the hypothesis that "task similarity and strategy relevance affect the potential generalizibility of the strategy," (p.211). Their findings also revealed that though content dependent learning can teach a specific skill it does not facilitate the "general application of the strategy to future related tasks as much as when it is learned in a content-independent situation" (Singer and Suwanthada, 1986, p. 211). 
These are but a few studies that have been conducted on transfex of learning from a primary task to related and less related tasks. The results of the studies relating to skill transference from task to related and less related tasks forms the basis from which to focus still further into the area of cognitive processes in transfer of learning. The next area of this section looks at the related research regarding visual and semantic versus semantic only encoding processes. Here the contention is to differentiate the cognitive factors involved in the thought process using these two techniques and how they relate to transfer of learning.

\section{Visual and Semantic versus Semantic only Encoding}

A number of assumptions can be found in the literature relating to the utilization of visual versus semantic training. These assumptions relate to the perceptions and cognitions developed via the encoding process and how these units of information are stored into long term memory. In the studies that follow we see not only how the information was received but also how it was stored in memory.

The process of how each method encodes and stores the learned knowledge or skills within the individual's memory is explained by Hunt (1978). He postulates that 
semantic encoding is the orderly sequencing of sensory images. This he bases on two assumptions: "that active thought is physically a succession of sensory images and that long term memory is functionally a network of semantic associations" (Hunt, 1978, p. 6). General information is best represented through organized information units that are referred to as "schemata". "Schemata are active interrelated knowledge structures actively engaged in the comprehension of arriving information guiding the execution of processing operations" (Rumelhart and Norman, 1978, p. 41). They differentiate "visual information" as being encoded in a separate fashion than semantic information. Visual information they indicate is a "deeper coding." The methodology for visual encoding used throughout this study shall include what is commonly referred to as experiential learning or "hands on learning" which in all actuality is visual learning.

A number of studies (Bederman, Glass \& Stacy, 1973; Palmer, 1975, Kosslyn, 1980; Block, 1981; Sless, 1981; Sternberg, 1985; and Szuchman, 1987) have concluded that "visual reinforcement" of stimuli increases probability of retention into long term memory. Long term memory is defined as the "permanent repository for semantic information" (Klatzky and Stoy, 1978, p.76). 
The probability that "visual imagery" can help in the formation of associations becoming an integral part of the mediational process and thereby facilitating recall was studied by Bugelski, Kidd, and Segmen, (1968). In their conclusions, they indicate that use of the rhyming techniques enhance recall in the experimental subjects when time requirements are such that a sufficient period of time is available for learning.

Klatzky and Stoy (1978) have defined "semantics" as the study of meaning independent of form. "Semantics implies independence from physical form" (Klatzky and Stoy, 1978, p.80). While according to Sternberg (1985), visual enhancement of learning, can be seen as a linking stage in the learning process between sensory reception and long-term retention. Sternberg (1985) advised that "verbal comprehension or semantic encoding is the physical linking of a linguistic message unit (a string of sounds or symbols) that stand as tokens for the conceptual words (or morphenes) in the language. Comprehension cannot proceed unless the physical tokens are associated with their concepts" (p. 1). Kosslyn (1985) points out that full comprehension cannot occur without a mental image of what the word implies. He advises that this 
requires some sort of visual image of the word to be established in the individual.

One study that focused on semantic constraints imposed by specific verbal context of response members of word pairs was that by Rohwer (1966). Selecting a population of six grade students, he studied the interaction of variables of meaningfulness, syntactic structure and semantic constraints.

Rohwer (1966) designed his research with fourteen different conditions and four sets of eight paired-associations, two for learning tasks and two for pretraining. With two groups serving as control groups, the remaining twelve received various manipulated levels of the three variables in training. The results of the study reflected that the visual association of the variables reduced the time needed to learn the material. Carol Conrad (1978) attributed this to isolable subsystems in semantic memory. Isolable subsystems refer to the numerous independent but interrelated memory subsystems for storing available information about words that lead to word recognition. Conrad (1978) advised that "factors that influence retrieval time for one system do not influence the time to retrieve information from other systems as wel1" (p.104). 
Summary

It has been the intent of this study to evaluate one treatment, content specific learning strategy, over another treatment, content general learning strategy. This study investigated these treatments across two distinct methodologies, visual and semantic encoding versus semantic only encoding. The purpose of this study was to determine if one treatment was more suitable for transfer of learning over a second treatment and if methodology of encoding the learning created any significant difference between the two treatments.

Literature on transfer of learning, evaluation of learning strategies and predictors of success in measuring the degree of transfer of learning from related tasks to less related tasks indicates the utilization of a content general or learning how to learn treatment to increase transfer of skill or learning. Singer and Suwanthada, (1986) advise that content specific learning is best for learning a specific task but that content general learning outperforms other strategies in the less related tasks and in transfer of learning skills.

The literature on methodologies for implementation of the treatment of learning or encoding the learning 
indicates that visual and semantic presentations outperform semantic only presentations of learning material. Sternberg (1985) and others have concluded that visual reinforcement of stimuli or learning material enhances learning into long term memory. 
CHAPTER III

METHODOLOGY

\section{Introduction}

The two basic purposes of this study were to: (a) evaluate the effect of the content specific learning strategies versus the content general learning strategies (treatment interventions) on increasing the retention and transfer of learning on a randomized sample of bank tellers; and (b) determine if the methodology of encoding the treatment intervention, visual and semantic encoding versus semantic only encoding yields more proportionate transfer of learning for either of the two learning strategies.

The study measured the degree of transfer of learning in the detection of counterfeit U. S. currency to the detection of altered U. S. currency and lastly to detection of forged U. S. Treasury checks. It commenced with the random selection of a number of tellers from several large banking establishment in Broward and Dade counties, Florida.

Population of the study

The study was conducted at the training centers of the participating Broward and Dade county banks 
involved in the study. The training was conducted on the average of twice a month for a period of five months.

A total of 300 subjects were selected from a number of banking establishments in Broward and Dade counties florida. The number of subjects in the random sample needed to maintain an appropriate medium effect size (.35) with power at .80 for an alpha level of $\mathrm{p}<.05$ was $\mathrm{N}=198$ (Cohen, 1977, p.384). A requirement for each treatment group was to have 33 participants; this was surpassed with 50 participants in each cell. The subjects were selected randomly from teller trainees and on line tellers. Subjects were randomly assigned to the classes, and the classes received treatments according to a random number chart. Any training session had an equal opportunity to be selected for any of the six different groups. In addition, the treatments were administered on a completely random basis.

The participating tellers ranged in experience from no experience handling currency to tellers with more than 20 years of currency handling experience. The vast majority (48\%) had from 2 years to 5 years experience. The largest percentage of tellers (52\%) were single. Regarding the variable of education, the majority (48\%), had a high school education or 
equivalent GED, 39 per cent had one to two years of college, and 5 per cent had a four year college education. The age breakdown of the subjects fell into four main categories: 17-25 years of age (35\%), 26-32 years of age $(27 \%), 33-42$ years of age $(25 \%), 43-74$ years of age (13\%). Females outnumbered males by almost a $3: 1$ ratio.

The first treatment group received content specific learning strategy with semantic methodology. The second treatment group received content specific strategy with a visual and semantic methodology. The third treatment group received content general strategy with semantic methodology. The fourth treatment group received content general learning strategy with visual and semantic methodology. The fifth treatment group served as a control group receiving the particular bank's traditional training but took the pretest and the posttest, while the sixth treatment group also served as a control group and received the posttest only in order to eliminate any bias from the pretest. It should be noted that the banking establishments involved in this study already gave some form of training in the identification of counterfeit currency using actual counterfeit notes.

The variable of prior training for some of the participants was controlled through the randomization 
process. All groups had an equal opportunity to include tellers who had some sort of prior training in the detection of counterfeit currency ( $44.2 \%)$.

\section{Instructional Intervention}

Methodology to perform this study included a pretest of the teller's knowledge of what to look for on a counterfeit note and how to detect them. In addition to this was the administrative requirements of both the U.S. Secret Service for the banking industry and some of the particular bank's policies and procedures relating to counterfeit currency. Following the instructional intervention, a posttest consisting of 30 questions was administered to the participating tellers from a bank of questions. The bank of questions included ten questions from the pretest to measure degree of learning, ten questions from a related topic, detection of altered U.S. currency, and ten questions dealing with a less related topic, detection of forged U. S. Treasury checks. The ten questions on altered U.S. currency measured the degree of transfer of learning from the instructional topic of detection of counterfeit currency to the detection of altered genuine money. This helped to determine the degree of transfer of learning that occurred to a related task. The ten questions relating to forgery of U. S. Treasury 
checks measured the degree of transfer of learning to a less related task.

The development of the pretest and posttest problems came from the input of a number of senior special agents of the U. S. Secret service and senior teller trainers from the training divisions of several of the major banks in Broward county, Florida. This group developed a list of twenty-three questions that were used for the pretest on the detection of counterfeit currency and the banking establishment's administrative guidelines for dealing with the detected currency.

\section{Research Design}

The design of the study employed an analysis of covariance (ANCOVA). Two control groups were used in this study. The first control group received the pretest and the posttest. The second control group received the posttest only, to avoid any pretest bias. Regarding pretest bias, Kerlinger (1986) advises that learning can occur from the administration of a pretest and thereby contaminate the control groups' effectiveness. The treatment groups consisted of: (a) a content specific learning strategies group across two levels of methodologies, one level being visual and semantic encoding and the second being semantic only 
encoding; and (b) a content general learning strategies group across the same two levels of methodology. The design to analyze the data was an analysis of covariance (ANCOVA). Exhibit 1 gives a treatment by method relationships with control groups.

\section{Exhibit 1}

Treatment Interventions

\begin{tabular}{|c|c|c|}
\hline & $\begin{array}{l}\text { Content } \\
\text { Specific }\end{array}$ & $\begin{array}{l}\text { Content } \\
\text { General }\end{array}$ \\
\hline $\begin{array}{l}\text { Visual \& } \\
\text { Semantic } \\
\text { Encoding }\end{array}$ & $\begin{array}{c}\text { Pretest } \\
+ \\
\text { Posttest }\end{array}$ & $\begin{array}{c}\text { Pretest } \\
+ \\
\text { Posttest }\end{array}$ \\
\hline \multirow[t]{3}{*}{$\begin{array}{l}\text { Semantic } \\
\text { only } \\
\text { Encoding }\end{array}$} & $\begin{array}{c}\text { Pretest } \\
+ \\
\text { Posttest }\end{array}$ & $\begin{array}{c}\text { Pretest } \\
+ \\
\text { Posttest }\end{array}$ \\
\hline & Control & Control \\
\hline & $\begin{array}{c}\text { Pretest } \\
+ \\
\text { Posttest }\end{array}$ & $\begin{array}{l}\text { Posttest } \\
\text { only }\end{array}$ \\
\hline
\end{tabular}




\section{Analysis of the Data}

The analysis of covariance (ANCOVA) was employed to determine the degree of relationship between the pretest and the posttest. A linear relationship was assumed to exist between the dependent variable (posttest score) and the covariate (pretest). The ANCOVA was used to determine the significance of any interactions occurring between the independent variables and the dependent variables of the posttest scores of the participants. The analysis of covariance (ANCOVA) determined the degree of relationship between the covariate of the pretest and the posttest.

The original pretest consisted of twenty three questions from a bank of questions covering the learning objectives of the lesson plans. These questions were developed by a modified delphi technique between two trainers and two administrators from two major banks in Broward county, Florida and three officials of the United States Secret Service (see Appendix B, the pretest). The U. S. Secret service, it should be noted, is the agency responsible for the investigation and detection of counterfeit money, forged U. S. Treasury checks and altered U.S. currency for the United States government. The bank officials and trainers are responsible to the participating 
establishments for ensuring quality training in the detection of counterfeit currency and forged checks. This same group developed the bank of questions to be used in the posttest. The posttest consisted of 30 questions. Ten of the questions were selected from the bank of questions covering the detection of counterfeit currency which were given on the pretest. These ten questions helped to establish a measurement for learning derived from the lessons. The second ten questions dealt with the detection of altered genuine U. S. currency and the banking industry's administrative procedures used once detection occurred. The last ten questions were drawn from a bank of questions relating to the detection of forged $U$. S. Treasury checks and the banking industry's administrative procedures in handling such items. The measurement instruments were subjected to a pilot study of tellers ranging in experience from none to over 20 years as a teller. The tellers and teller trainees used in the pilot study were all randomly selected from the participating banks located throughout Broward County, Florida. The total subjects for the Pilot study were, for the Pretest $N=39$, and for the posttest $N=38$. A half hour time limit was imposed on all participants per test. From the total number of participants in the pilot study, 9 subjects 
took only the pretest to act as a control group, 30 took the pretest and the posttest and 8 took only the posttest to control for any bias from the pretest.

Upon arrival, subjects were seated at separate tables and provided with a pencil and answer sheet. After a brief introduction to the type of test they were to take, the test sheets were distributed. While the subjects took the tests the experimenter was available to answer questions or assist subjects having a problem in answering a particular question.

The utilization of a pilot study with a split-half reliability test helped establish the reliability coefficient to be used in the measurement of the data gathered from the later tests. The pilot was employed to determine alpha reliability for the pretest. The testing instrument was designed to measure the tellers' ability to transfer training from a primary learning task to a related task and to a less related task. As Gay (1987) notes: "high reliability indicates minimum error variance" (p. 135). A split-half reliability procedure was used to compute each subject's score on the two halves of the pretest and the posttest. Gay (1987) advises that "if the coefficient is high, the test has good split-half reliability" (p. 139). The Spearman-Brown prophecy formula was used as the correction formula for the split-halves testing 
procedure. An analysis of the pilot study results reflected a split half reliability of .710 for the pretest and .870 for the posttest using the correction equation from the spearman-Brown prophecy formula. Due to the lower reliability alpha for the pretest an item analysis was conducted which indicated the need to adjust several of the questions from the pretest instrument.

The results of the pilot study provided the basis for several revisions of the instruction, materials, and testing instruments. These revisions took the form of simpler vocabulary and more specific examples. One of the original 23 questions on the pretest was eliminated as an odd number of questions made the use of the correction formula difficult to administer. However, the results did indicate that the subjects were able to answer a number of the questions in each of the three separate tasks and that transfer of learning did occur.

The posttest was subjected to a split-halves alpha reliability test on each of the separate ten questions making up the measured items of primary, related and less related tasks. An analysis of the three separate sections of the posttest reflected a split-half reliability of .500 for the primary task learning set of questions, .700 for the related task 
learning set of questions, and .830 for the less related task learning set of questions using the correction equation from the Spearman-Brown prophecy formula.

Appendix $B$ is the amended pretest consisting of 22 questions. Appendix D, is the posttest covering detection of altered genuine U. S. currency and the detection of forged U. S. Treasury checks. Content validity of test questions (how well the questions represent measurement in the intended content area) were evaluated through expert judgment as per Gay (1987, p. 130). Those experts represented both the banking industry as well as the U. S. Secret service and insured that "all subareas were included, and in correct proportions," (Gay, 1987, p.130).

The pretest was administered prior to any of the subjects receiving instructional treatment in the detection of counterfeit currency. The regular class trainer administered the test. The trainer was briefed not to give any instructional assistance other than how to fill in the answer forms.

The subjects included trainees having no experience of any kind with teller work as well as tellers with many years of experience at their respective banks. Training was conducted for a three-hour period. The posttest due to possible 
problems with retention was not administered later than two days following the training, (Cotton and klatzky, 1978) .

\section{Training Procedures}

The treatment consisted of content specific learning strategies and content general (learning how to learn) learning strategies delivered along two methodologies: visual and semantic encoding and semantic only encoding.

The first treatment group consisted of content specific learning strategies utilizing semantic only encoding, (CSSE). The content specific learning strategy using the visual and semantic encoding (CSVE) used actual counterfeit currency obtained from the vaults of the $U$. S. Secret service and a fifteen minute video presentation entitled "know your money." This was a training presentation for special agents of the Secret Service in the detection of counterfeit currency. Subjects were allowed to handle and examine closely different denominations of counterfeit U. S. currency and were shown defects which appeared on them and how to detect them. The three-hour training period was included in the regular teller training program for new employees and in special classes arranged with the participating banking establishments. The training was 
conducted twice a month for a five month period. The classes were augmented by instruction from a special agent of the U.S. Secret Service. To control for trainer skill in delivery method only one trainer was used. The CSSE treatment used the same video presentation on "Know your money" but did not use actual specimens of counterfeit currency or any close up photographs of counterfeit notes. No visual representations were used. Again the training period covered three hours of class time.

The second treatment group using content general learning strategies also used two distinct methodologies: (a) semantic only encoding (CGSE) and (b) visual and semantic encoding (CGVE). In the CGVE treatment, the subjects received training on the detection of counterfeit currency and also were taught metacognitive procedures (learning how to learn). Feedback was applied after presentations covering ways subjects could develop elaboration skills and strategies for learning (Weinstein, 1975, 1987). Metacognitive processes were discussed with the subjects during the training session. Also questions were asked of the participants requiring them to tell why they thought a currency note was counterfeit and how they reached their conclusions. Visual enhancement was achieved for the CGVE group by use of the video 
presentation "know your money," by pointing out features on oversized reproductions of currency, and by passing out actual counterfeit currency. Again, all participants were requested to give feedback and received feedback on discussions concerned with both specifics of the task and learning how to learn. The second method group, CGSE, also was given feedback on strategies for learning how to learn and was questioned on the metacognitive processes they used to reach conclusions and what made them think about elements of thoughts that helped them conceptualize their tasks. The CGSE group did not receive any actual counterfeit money to look at nor was it shown any distinguishing photographs of counterfeit currency. Encoding of information was from lecture and audio visual media. The total time training for both of these groups was the same as that for the CSSE and CSVE groups, although the content specific learning strategies groups did have more time devoted to counterfeit "per se" than the content general learning strategies groups. 
CHAPTER IV

PRESENTATION AND ANALYSIS OF DATA

\section{Introduction}

The measurement instruments were subjected to a pilot study of tellers ranging in experience from none to over 20 years as a teller. The tellers and teller trainees were all randomly selected from Sun Bank South Florida, N. A. The total subjects for the pretest $N=39$, and for the posttest $N=38$. A thirty minute time limit was imposed on all participants per test. From the total number of participants in the pilot study, 9 subjects took only the pretest to act as a control group, 30 took the pretest and the posttest and 8 took only the posttest to control for any bias from the pretest.

A split-half analysis of the pilot study results reflected a reliability alpha of .704 for the pretest and .869 for the posttest using the correction equation from the Spearman-Brown prophecy formula. Due to the lower reliability alpha for the pretest an item analysis was conducted which indicated the need to adjust several of the questions from the pretest instrument. 
The results of the pilot study provided the basis for several revisions of the instruction, materials, and testing instruments. These revisions took the form of simpler vocabulary and more specific examples. One of the original 23 questions on the pretest was eliminated as an odd number of questions made the use of the correction formula difficult to administer. However, the results did indicate that the subjects were able to answer a number of the questions in each of the three separate tasks and that transfer of learning did occur.

Two tests of significance were used to obtain inferences relating to quantification of data. The factorial analysis of covariance (ANCOVA) was used to detect any significant differences in the means of the covariates of the pretest and the posttest. Planned comparisons between groups were used to detect any differences in variance in the distribution of the scores of the groups.

Several assumptions must be made to set the parameters for any decision making processes. Likewise, there are certain assumptions which underlie the concept of the analysis of covariance which also sets a distinct set of limitations on decisions dependent upon related findings. The specific assumptions which underlie the analysis of covariance 
are summarized as: (1) the dependent variable is normally distributed in each group, (2) the population variances for the groups are equal, (3) the observations are independent, (4) there is a linear relationship between the dependent variable and the covariate, (5) the slope of the regression line is the same for each group, (6) the covariate is measured without error (Stevens, 1986). (It should be noted that items 1, 2, and 3 are the assumptions for ANOVA.)

As Dowdy and Wearden (1983, p. 383) point out, the factorial analysis of covariance (ANCOVA) is a "combination of regression analysis with an analysis of variance. Covariance is used when the response variable $y$, in addition to being affected by the treatment, is also linearly related to another variable x." The ANCOVA technique adjusts the dependent variable in two or more groups to what it would be if all groups had started out equally on the covariate and then tests for significant differences between the adjusted means. The use of the ANCOVA, as Dowdy and Wearden (1983) have alluded, helped increase precision in the experiment, added control for extraneous variables in the survey, and compared the regression within the groups.

As Stevens (1986, p. 302) explains, when there are 
"several covariates, the amount of error reduction is determined by the magnitude of the multiple correlation between the dependent variable and the set of covariates (predictors)." It is for this reason that covariates should have low intercorrelations amongst themselves, to achieve a greater error reduction.

Even though many of the subjects in the different groups started out unequal in knowledge of the subject and individual ability, the adjustment of the means on the posttest scores to what they would be if the pretests were all equal, allowed the analysis to reflect if it was the treatment that caused any differences and not prior knowledge of the subject.

In this study, the experimenter in order to test for the assumption of homogeneity of regression (parallel within group regression lines) in an analysis of covariance, tested the null hypothesis of no difference between the population regression parameters.

As with the ANOVA the ANCOVA holds that a given observation may be partitioned into dependent and additive bits, each bit resulting from an identifiable source. 
The Sample

For drawing inferences about the characteristics of the general teller population from statistics, the sample population of tellers was taken at random from a number of participating banking establishments throughout Broward and Dade Counties, Florida. The sample of participating tellers is referred to in this dissertation as "the sample." Thus, the technique of sampling used allowed every member of the teller population of the participating establishments an equal probability of being included in it and every member of the random sample an equal chance of inclusion.

The sample ranged from 17 years to 74 years of age. For the variable of native language the majority of the random sample (68\%) listed English, they were followed by those listing Spanish (26\%), the remainder (6\%) were divided between French, Haitian, Italian, German, and other. The level of education showed that the largest portion of the sample (48\%) had a twelfth grade education, followed by those with one year of college (20\%). Subjects with two or more years of college (19\%) had the third highest percentage of inclusion with $11.7 \%$ making up the remainder. For the variable of experience as a teller, the sample ranged from 30 percent 1 isting $0-6$ months experience to 21 
percent listing over five years as a teller. From the sample, 81 percent listed that they had had some sort of related experience prior to becoming a teller, either as a retail cashier or working in some sort of financial organization. The predominant sex, was female $(75 \%)$, and over half $(52 \%)$ of the entire sample were single. Regarding the variable of prior training in the detection of counterfeit currency, 55.8 percent reported no prior training, while the remainder of the sample reported that they had had some type of prior training.

\section{Analysis procedures}

Tests were developed using reasonable sample sizes to provide adequate test power, as per Cohen (1977) and Stevens (1986). A medium effect size of over .35 was suggested from the literature and with a six group study, according to Cohen (1977 p. 384) 33 subjects per cell size ( $N=198)$ would be needed to maintain an alpha of $\mathrm{p} .<.05$ with power at the .80 level.

\section{Explanation of the Pretest}

Prior to testing the null hypotheses an examination of the pretest scores is given in Table 1. The first table describes a comparison of group scores on the pretest, listing their means, standard 
deviations, $F$ ratios and the significance of the $F$ value at the $\mathrm{p}<.05$ level of alpha. The analysis reflected that group 2 scored higher on the pretest than all other groups but that there were no significant differences between groups, (see Table 1).

The data compiled during the study confirm the findings of the pilot study regarding the reliability of the testing instrument used for the pretest. The range of means ran from a low of 12.551 for group 4, the content general learning strategies group with visual and semantic encoding (CGVE) to 13.520 for group 2 , the content specific learning strategies with visual and semantic encoding (CSVE). The $F$ ratio for the difference between groups on the pretest scores was 1.0698 with a significance of $F$ at .3720 at the $p<.05$ level of alpha.

A relationship was found to exist between the sample's pretest score and the score they obtained on three sets of measured items on the posttest. As the data provided in Table 1 shows there were no significant differences between the groups on pretest scores. The randomized selection to the groups and the randomization of the treatments to the groups was done to insure equal represenation of the sample. 
Table 1

Comparison of Groups on Pretest Scores by Means, Standard Deviations, $F$ Ratios and Significance of $F$

\begin{tabular}{|c|c|c|c|c|}
\hline \multirow{2}{*}{\multicolumn{2}{|c|}{ Groups }} & \multicolumn{3}{|c|}{ Pretest Scores } \\
\hline & & Means & std Dev. & $\mathbf{N}$ \\
\hline 1 & CSSE & 13.367 & 2.489 & 49 \\
\hline 2 & CSVE & 13.520 & 2.908 & 50 \\
\hline 3 & CGSE & 12.940 & 3.040 & 50 \\
\hline 4 & CGVE & 12.551 & 2.574 & 49 \\
\hline 5 & Control & 13.468 & 2.977 & 49 \\
\hline For & Entire Sample & 13.167 & 2.808 & 246 \\
\hline
\end{tabular}

$F$ ratio $=1.0698 \quad$ Significance of $F=.3720$

Testing the First Null Hypothesis

The results of the analysis of covariance under the seven hypotheses stated in chapter one are reported in what follows:

Hypothesis (1). There is no significant difference between content general learning strategies and content specific learning strategies on the degree of transfer of learning to related and unrelated tasks. For analysis purposes the hypothesis was reformulated as follows: 
$\mathrm{H}_{\mathrm{O}}$ : The difference between the mean posttest score of the groups receiving content general learning strategies and the groups receiving content specific learning strategies equals zero.

$\mathrm{H}_{1}$ : The difference between the mean posttest score of the groups receiving content general learning strategies and the groups receiving content specific learning strategies does not equal zero.

Table 2 focuses on the comparison of means, standard deviations, $F$ ratios and significance values achieved by the six groups on the measured items of the posttest. The data on primary, related and less related tasks were subjected to an ANCOVA procedure. A linear relationship was found to exist not only between the pretest and the posttest scores but between the primary learning task (the first 10 questions of the posttest) and the related learning tasks (the second 10 questions from the posttest). There was also a relationship between primary and related tasks to less related tasks (the last 10 questions on the posttest).

As Table 2 shows, the group which scored the highest performance on the primary task learning was group 2 , content specific with visual and semantic 
encoding (CSVE). Their mean score was 9.140 for the primary task. However, for related tasks, group 4, content general with visual and semantic encoding, (CGVE) scored higher than all other groups with a mean of 8.680 . Group 4 also outperformed all other groups on the third set of questions on the posttest, (less related tasks) with a mean of 8.420 . These were significantly different scores than all other groups for all of the measured items of the posttest, thus the first null hypothesis of this study is rejected.

Even though group 2 (CSVE) outperformed group 4 (CGVE) on the primary learning task, it did not outperform group 4 (CGVE) on transfer of learning measured by related tasks or less related tasks, (the second and third measured items of the posttest). Group 4 (CGVE) outperformed all other groups on the items measuring transfer of learning and was followed on these tasks by Group 2 (CSVE) for the related task items and Group 3 content general and semantic encoding (CGSE) on the less related task items of the posttest. This would indicate that the use of general learning strategies enhances the transfer of learning, as does the use of visual and semantic encoding. It should also be noted that all four treatment groups outperformed the two control groups on the measured items of the posttest. 
As Kerlinger (1986) points out, the larger the between variance in relation to the within, the larger will be the $F$ ratio and the more likely

Table 2

Comparison of Posttest Means, Standard Deviations for the Four Treatment Groups and Two Control Groups Across the Three Measured Items of Primary, Related and Less Related Tasks.

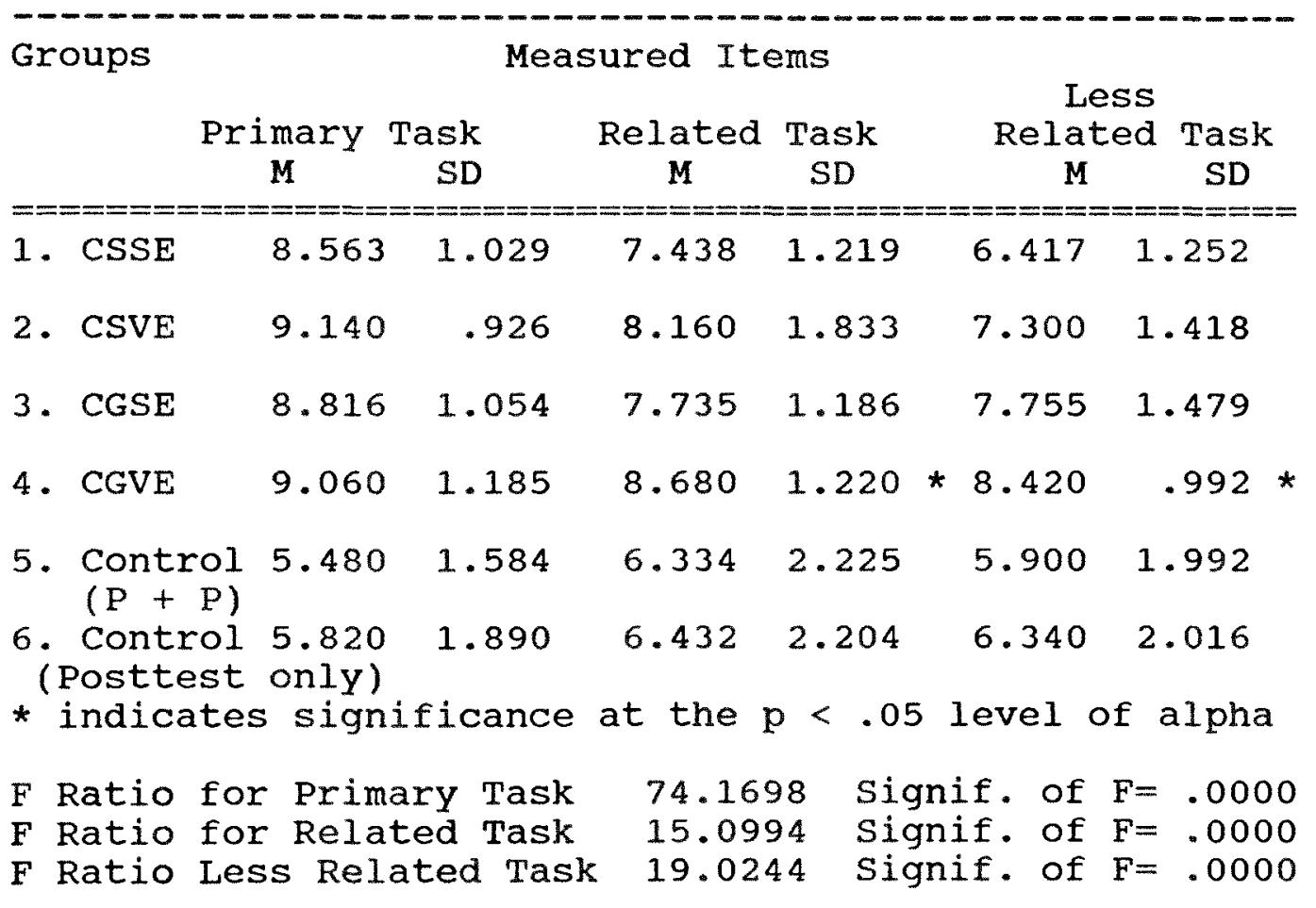

there will be significant findings. The $F$ ratio for differences between groups on the primary task was 74.1698 , for the related tasks it was 15.0994 and for less related tasks it was 19.0244 , all with significance of $F$ values of .0000 at the $p<.05$ level of alpha. Group 2 (CSVE), although not significantly different than the three other treatment groups on the 
first set of questions reflecting primary task learning did outperform the other three groups. This performance was not maintained however when transfer of learning was measured. As can be seen from Table 2, there exists a significant difference between the groups. Group 4 and group 3 representing the content general learning strategies significantly outperformed the content specific learning strategy groups. This supports rejecting the first null hypothesis of this study: that there were no significant difference between content general learning strategies and content specific learning strategies on the degree of transfer of learning to related and unrelated tasks. Table 2 reveals that of the four treatment groups group 1 (CSSE) produced the lowest scores on all measured item set of questions. Table 2 also reveals that the four treatment groups were all significantly different than the two control groups which received the banks traditional training.

Table 3 reflects the analysis for comparison purposes of the data between treatments of content specific and content general learning strategies on the measured items of the posttest of primary, related, and less related tasks. The data, as reported in Table 1 , reveal that the content specific groups (group 1 and group 2) outperformed the sample in the content general 
groups (group 3 and group 4) on the pretest. However, Table 3 reveals that on the measured items of the posttest the average scores of the content general groups outperformed the content specific groups across all three measured items of the posttest. The only significant differences though, appeared on the less related task measured items with an $F$ ratio of 44.1053 and a significance of $F$ of .0000 at the $p<.05$ level of alpha. (See Table 3 a comparison of treatment groups.)

Table 3

Comparison Between the Treatment Groups of Content specific and Content General Learning Strategies Across the Measured Items on the Posttest of Primary, Related, and Less Related Tasks.

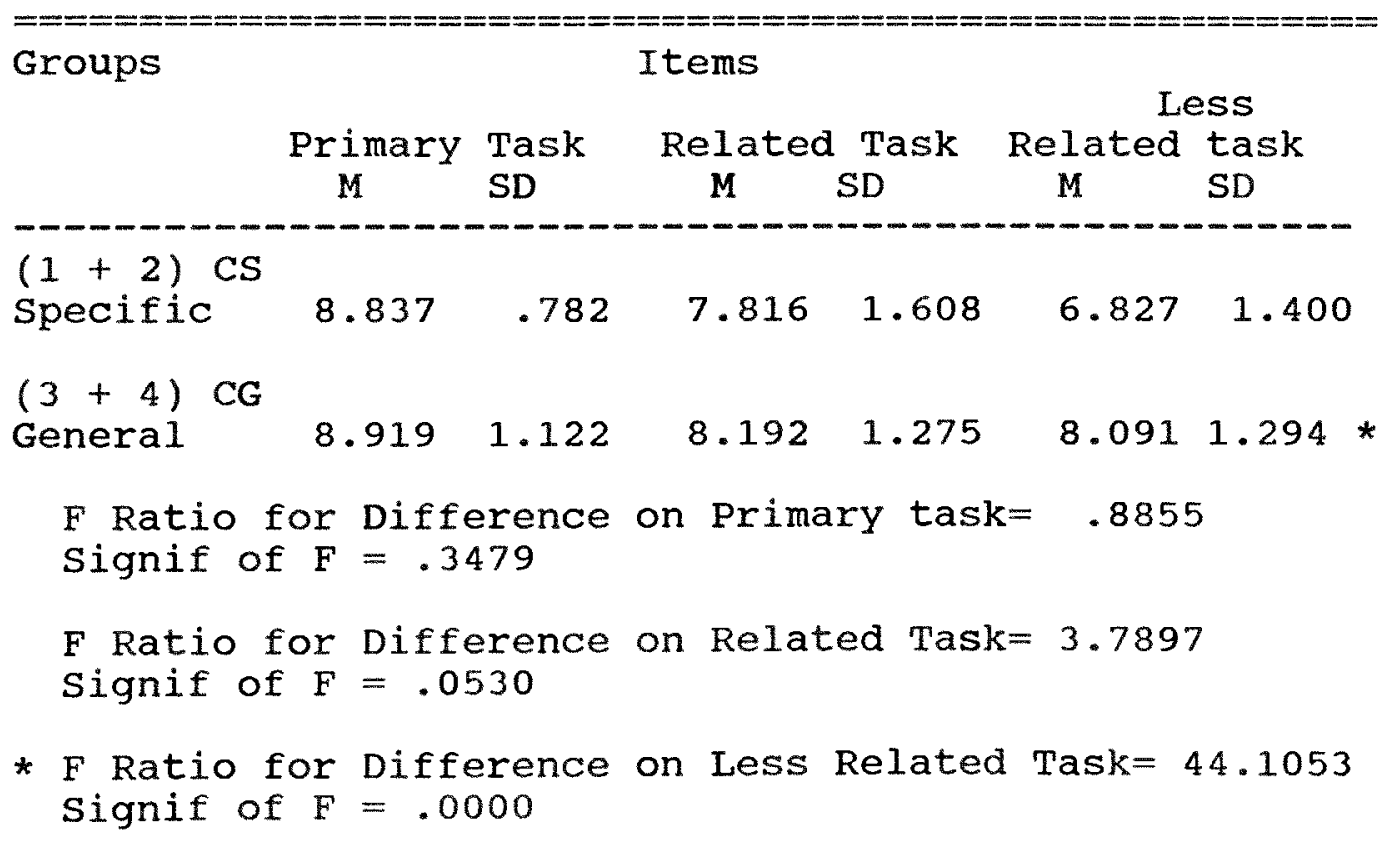


Across all measured tasks the treatment differences became apparent. The mean scores of the two treatment groups receiving content general learning strategies reflected a higher mean regardless of the method of encoding of the learned material. These findings indicate that the use of learning strategies by the random sample enhanced their ability to learn related and less related tasks more effectively.

Testing the second Null Hypothesis

The results of the ANCOVA on the data had a direct bearing on the second null hypothesis formulated in this study. That hypothesis dealt with the differences between visual and semantic encoding versus semantic only encoding: Hypothesis (2). There is no significant difference between visual and semantic encoding methods (actually viewing the counterfeit money during training sessions) versus semantic only training methods (lecture/media only) on the degree of transfer of learning which occurs on the posttest.

For analysis purposes the hypothesis was reformulated as follows:

$H_{0}:$ The difference between the mean posttest score of the groups receiving visual and semantic encoding and the 
groups receiving semantic only encoding equals zero.

$\mathrm{H}_{1}$ : The difference between the mean posttest score of the groups receiving visual and semantic encoding and the groups receiving semantic only encoding does not equal zero.

Table 4 shows a comparison between the mean of the visual and semantic encoding groups, (group 2 CSVE and group $4 \mathrm{CGVE}$ ) and the semantic only encoding groups (group 1 CSSE and group 3 CGSE).

The obtained $F$ for the between groups difference on the primary task was 9.000 with a significance of $F$ of .0300 . The obtained $\mathrm{F}$ for the between groups difference on the related task was 16.9659 , with a significance of $F$ of .0001 . The obtained $F$ ratio for the less related task was 15.1695 with a significance value of .0001 at the $p<.05$ level of alpha. Therefore, the stated second null hypothesis of this study is rejected.

The between groups variance for the combination of group 2 (CSVE) and group 4 (CGVE), representing the visual and semantic encoding group, and the combination of group 1 (CSSE) and group 3 (CGSE), representing the semantic only encoding group, reflected significantly 
different scores across all measured items of the posttest. These results show that the visual and semantic encoding group significantly outperformed the semantic only encoding group on all measured items. These data (See Table 4) support the hypothesis that visual and semantic encoding is a more effective method of encoding for learners when learning new material. These findings indicate that any significant differences appearing on the measured items of the posttest are the results of the treatments (content general or specific learning strategies), the methods of encoding (visual and semantic or semantic only encoding) or some interaction between the treatments and the methods put forward in this study. The visual and semantic encoding groups scored higher in correct responses across all levels of tasks regardless of treatment, whether content general or content specific (see Table 4). Visual enhancement contributed significantly to the overall transfer of learning achieved by the CGVE group with a F of .0001 at the $p<.05$ level of alpha significance. Therefore, the second null hypothesis was rejected in favor of the alternative hypothesis which assumed that "visual and semantic encoding" does significantly differ from "semantic only encoding" on the transfer of learning, (see Table 4). 


\section{Table 4}

Comparison Between Semantic only Encoding and visual and Semantic Encoding Across the Measured Items of Primary, Related and Less Related Tasks.

Groups

Posttest Measured Items

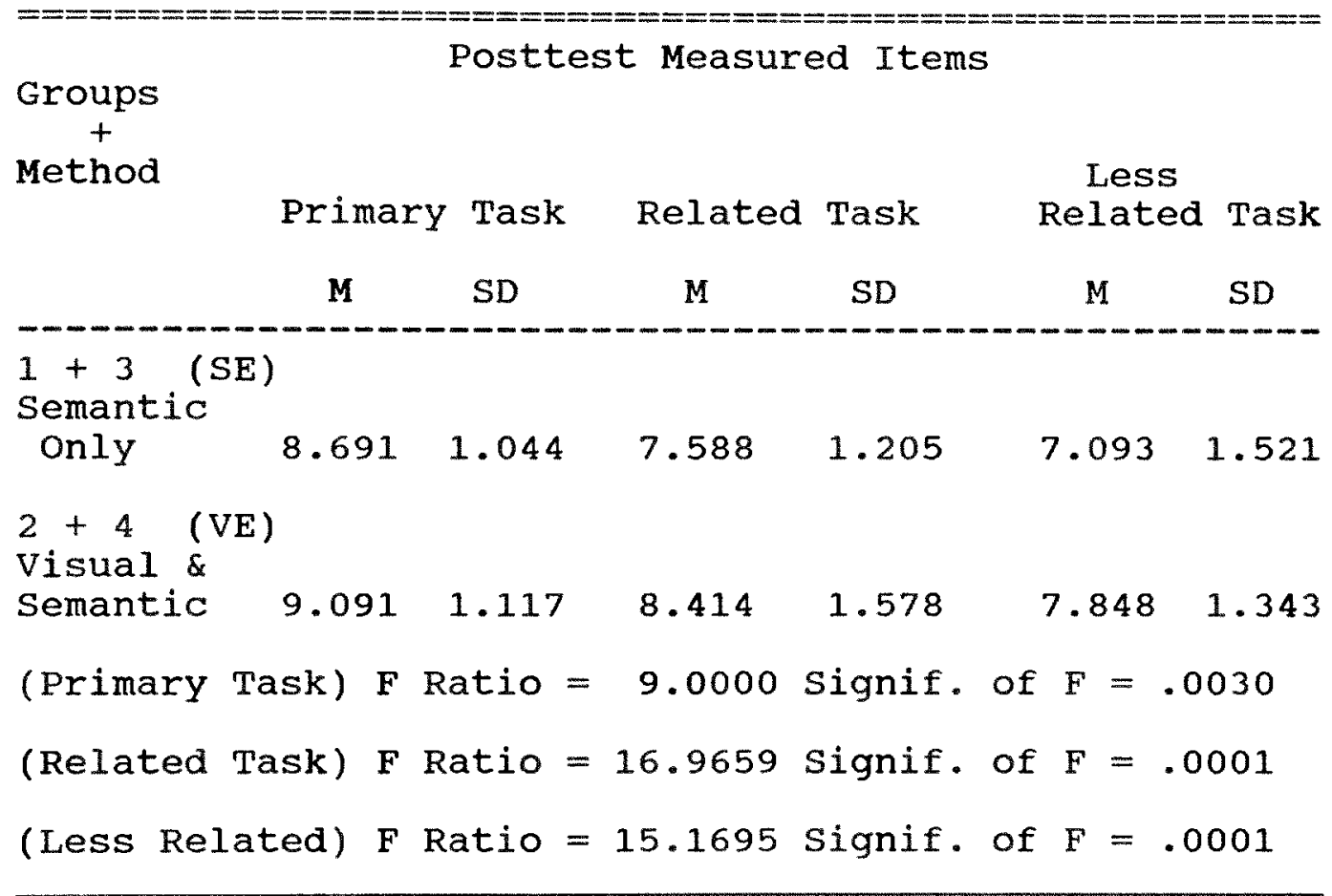

Testing the Third Null Hypothesis

Table 5 is a comparison of the sample population's $(N=300)$ performance on the measured items of related and less related tasks reflecting means, standard deviations, standard error, and 2 tailed probability at the $\mathrm{p}<.05$ level of alpha.

The results of the paired t-test shown in Table 5 support rejection of the third null hypothesis formulated in this study. The third null hypothesis is restated here for clarification purposes. 
Hypothesis (3). There is no difference existing in the degree of transfer of learning due to similarity of task. For analysis purposes the hypothesis was reformulated as follows:

$H_{\circ}: \quad$ The difference between the mean scores received on the measured items of related and less related tasks equals zero.

$H_{1}$ : The difference between the mean scores received on the measured items of related and less related tasks does not equal zero.

A 2 tailed paired t-test at the $p<.05$ level of alpha was conducted to determine the mean difference between the pretest and the postest.

\section{Table 5}

Comparison of the Sample Population $(N=300)$ on the Measured Items of Related and Less Related Tasks by Mean, Standard Deviation, Standard Error Reflecting the Mean Difference and the 2 Tailed Probability.

\begin{tabular}{|c|c|c|c|c|}
\hline Tasks & Mean & std Dev. & Std Error & $\mathbf{N}$ \\
\hline Related Tasks & 7.4700 & 1.887 & .109 & 300 \\
\hline $\begin{array}{l}\text { Less Related } \\
\text { Tasks }\end{array}$ & 7.0233 & 1.796 & .104 & 300 \\
\hline Mean Difference & .4467 & 1.909 & .110 & \\
\hline
\end{tabular}


As Table 5 reflects the means significantly differ between related and less related tasks regardless of the learning strategy or method of encoding used. It was determined that the probability of the differences was significant at .0000 (see Table 5). Therefore, the stated third null hypothesis of this study was rejected.

As can be seen from the data in Table 5, regardless of strategy or method, the mean scores were lower across groups for less related tasks than from related tasks. This supports the hypothesis that the random sample would perform more effectively on related task transfer of learning over less related task transfer of learning.

A significant linear relationship was found to exist between the measured items of the posttest of related and less related tasks. This indicated that the higher a subject scored on the related task items of the posttest the higher the subject would score on the less related task items of the posttest.

Testing the Fourth Null Hypothesis

The effect of the selected independent variables did explain significant amounts of variance in the dependent variable of the posttest. The results of the ANCOVA procedure on the scores of the sample on the 
three sets of measured item questions support the rejection of the fourth null hypothesis formulated in this study. The fourth null hypothesis is reported here for clarification purposes. Hypothesis (4). There is no significant difference in the posttest item task scores which measure transfer of learning due to the independent variable of level of education. For analysis purposes the hypothesis was reformulated as follows:

$H_{\circ}: \quad$ The difference on the posttest measured item scores according to a subject's level of education equals zero.

$\mathrm{H}_{1}$ : The difference on the posttest measured item scores according to a subject's level of education does not equal zero.

Table 6 is a comparison of the selected independent demographic variables' effect on task performance by $F$ ratio and significance of the $F$ value for the posttest scores. Planned comparisons of the demographic independent variables were conducted to determine how they contributed to the within group variance. One of the variables assumed to contribute significantly was the level of education, which formed the fourth null hypothesis of this study. This 
variable significantly contributed to group variance on the measured items on the posttest of primary task learning and related task learning. It did not, however, contribute to a significant difference for less related task learning. The $F$ ratio for level of education was 4.4241 for the primary task, with a probability of $\mathrm{F}$ at .0017 . For the related tasks the level of education had an $F$ ratio of 3.7012 with a probability of $\mathrm{F}$ at .0059 . For less related tasks the level of education had an $F$ ratio of 1.4106 with a probability of $\mathrm{F}$ at .2309 . No two groups were significantly different on the less related tasks at the $\mathrm{p}<.05$ level of alpha. It should be noted, however, that the four year college level was significantly different then the high school graduate level. The other levels of higher education did not significantly differ from the high school graduate. This indicates that a subject's education level can have a significant influence on learning but that it does not necessarily contribute significantly to transfer of learning with less related tasks, (see Table 6). 


\section{Testing the Fifth Null Hypothesis}

The results of the ANCOVA shown in Table 6 support the rejection of the fifth null hypothesis formulated in this study. The fifth null hypothesis is reported here for clarification purposes.

Hypothesis (5). There is no significant difference in the posttest item task scores measuring the degree of transfer of learning due to the independent variable of experience as a teller. For analysis purposes the hypothesis was reformulated as follows:

$H_{0}: \quad$ The difference on the posttest measured item scores according to experience as a teller equals zero.

$\mathrm{H}_{1}$ : The difference on the posttest measured item scores according to experience as a teller does not equal zero.

The variable of experience as a teller, (see Table 6) reflected a significant contribution to the variance of the sample on the performance of the posttest's measured items of both primary and less related tasks. The results indicate that the more experience tellers had the more effectively they performed on the measured items of the posttest. Each sequential level of experience outperformed 
Table 6

Comparison of Independent Variables' Effect on Task Performance by $F$ Ratio and Significance of $F$ from Planned Comparison Procedures.

\begin{tabular}{|c|c|c|c|c|c|c|c|}
\hline \multirow[t]{3}{*}{ Variable } & \multicolumn{7}{|c|}{ Measured Item } \\
\hline & Primary & Task & & Related & Task & $\begin{array}{c}\text { Less } \\
\text { Related }\end{array}$ & Task \\
\hline & F Sig & of $F$ & & Sig & of $F$ & F Sig & of $F$ \\
\hline $\begin{array}{l}\text { Level } \\
\text { Education }\end{array}$ & 5.0688 & .0006 & * & 3.8100 & $.0049 *$ & 1.6169 & .1700 \\
\hline $\begin{array}{l}\text { Teller } \\
\text { Exper. }\end{array}$ & 5.0104 & .0021 & * & 2.0281 & .1101 & 8.8924 & $.0000 *$ \\
\hline $\begin{array}{l}\text { Related } \\
\text { Exper. }\end{array}$ & 1.8907 & .1312 & & .3115 & .8171 & 2.0204 & .1111 \\
\hline $\begin{array}{l}\text { Prior cft } \\
\text { Training }\end{array}$ & .0735 & .7865 & & .1123 & .7377 & 1.3963 & .2383 \\
\hline
\end{tabular}

* The education level for 4 years of college significantly outperformed the 12 school years level on primary and related tasks.

* Tellers with more than 6 months experience significantly outperformed tellers with 6 months or less experience on primary and less related tasks.

the next lower level across all measured items of the posttest. There were significant differences on both the primary task and the less related task items.

Testing the Sixth Null Hypothesis

The ANCOVA procedure was used to test the sixth null hypothesis formulated in this study which is reported here for clarification purposes. Hypothesis (6). There is no significant differences between the independent variable of related experiences 
for the sample population that will effect the degree of transfer of learning between related and less related tasks. For analysis purposes the hypothesis was reformulated as follows:

Ho: The difference on the posttest measured items tasks according to the variable of related experience equals zero.

$\mathrm{H}_{1}$ : The difference on the posttest measured item tasks according to the variable of related experience does not equal zero.

The results of the ANCOVA procedure do not support the rejection of the sixth null hypothesis of this study. The variable of related experience did not reflect a significant $F$ value on any of the measured item tasks of the posttest. When considering the independent variable of related experience as either a retail cashier or work in a financial organization, no two groups were significantly different at the $p<.05$ level of alpha (see Table 6).

Testing the Seventh Null Hypothes is

The ANCOVA procedure was used to test the seventh null hypothesis formulated in this study. The seventh 
null hypothesis is reported here for clarification purposes.

Hypothesis (7). There is no significant difference in the posttest item task scores measuring the degree of transfer of learning due to the independent variable of prior training in the detection of counterfeit currency. For analysis purposes the hypothesis was reformulated as follows:

$\mathrm{H}_{\mathrm{o}}$ : The difference on the posttest measured item task scores measuring transfer of learning due to the independent variable of prior training in the detection of counterfeit currency equals zero.

$\mathrm{H}_{1}$ : The difference on the posttest measured items task scores measuring transfer of learning due to the independent variable of prior training in the detection of counterfeit currency does not equal zero.

The results of the ANCOVA procedure do not support the rejection of the seventh null hypothesis of this study. The variable of prior training in the detection of counterfeit currency did not reflect a significant $F$ value on any of the measured item tasks of the posttest. When considering the independent variable of 
prior training in the detection of counterfeit currency, no two groups were significantly different at the $p<.05$ level of alpha (see Table 6).

Pretest-Posttest Comparison of Independent Variables

Table 7 reflects a comparison of the adjusted means and standard deviations of the four selected demographic independent variables measured in this study across both the pretest and the posttest. As can be seen from Table 7 no two groups were significantly different on the pretest for the level of education. on the variable of level of education for the set of questions reflecting the measured item task of primary learning the college graduate level (mean $=9.308$ ) significantly outperformed the high school graduate $($ mean $=8.026)$. A similar significant difference appeared on the set of questions forming the second measured item of the posttest, related tasks. The college graduate level (mean $=8.769)$ significantly outperformed the high school level (mean $=7.479$ ). There were no significant differences for this variable on the set of questions forming the third measured item of the posttest, the less related tasks.

For the variable of experience as a teller Table 7 shows there were no significant differences on the pretest. On the posttest's set of questions forming 
the first measured item, the primary task the group of tellers with more than six months but less than two years $($ mean $=8.618)$ significantly outperformed both the group of tellers with less than six months experience (mean $=7.657)$ and those tellers with more than five years experience $($ mean $=8.053)$. There were no significant differences for the set of questions forming the second measured item, related tasks for this variable. For the third set of questions forming the measured item of less related tasks all groups of tellers above six months of experience outperformed the group of tellers with six months or less experience $($ mean $=6.403)$.

For the variable of related experiences the group which had worked in a financial organization prior to working as a teller (mean $=13.962$ ) significantly outperformed those tellers who had worked in retail stores prior to becoming a teller (mean $=12.774)$ on the pretest. There were no significant differences on any of the measured item tasks of the posttest for this variable.

For the variable of prior training in detecting counterfeit currency there were no significant differences on either the pretest or any of the measured item tasks of the posttest. 
Table 7

Comparison of Independent Variables on the Pretest and the Posttest by Adjusted Means and Standard Deviations.

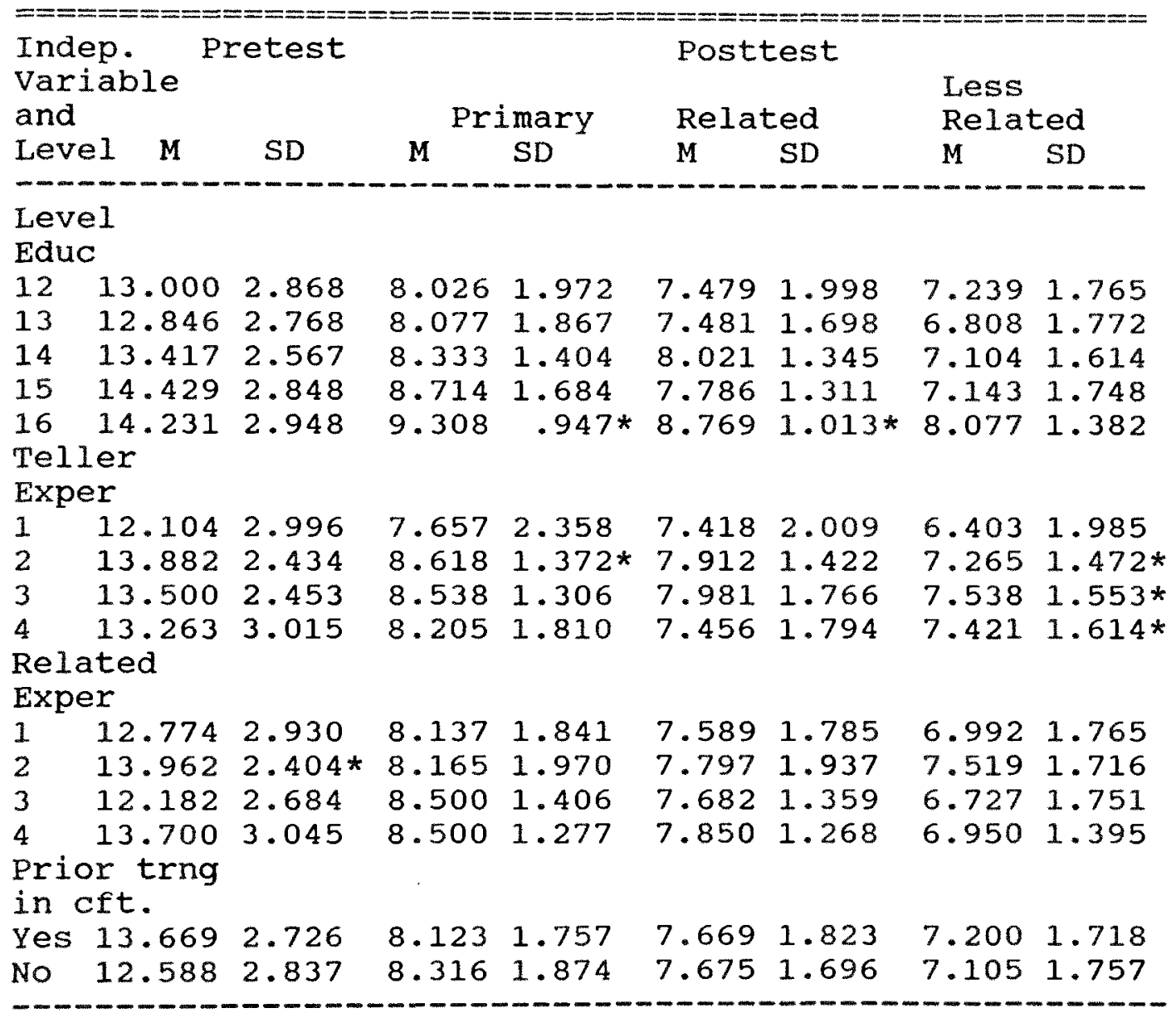

* Indicates significance at the $p<.05$ level of alpha.

Level of Education is reflected as years of education. Level of Experience: $1=0-6$ months; $2=>6$ months2 years; $3=>2$ years -5 years; $4=>5$ years.

Related Experience: 1 = retail, 2 = financial organization, 3 = other, $4=$ none. 
Introduction to Exhibit 2

Exhibit two is a comparison of the four treatment and two control groups over the three measured items of the posttest, primary, related and less related tasks. The Exhibit uses a normalized $t$-score to plot the changes over the three separate sections. A normalized $t$-score was used due to the difference in variance of the three measured items. As Hopkins and Glass (1978, p. 101) point out, the normalized $t$-scores are the most commonly used standard-score scale for reporting performance. The $t$-score scale has the equation mean equal 50 and standard deviation equal 10, multiplied by the " $z$ " score $(t=50+10(z))$. The $t-s c o r e$, always rounded off to two figures, does not employ the use of decimals or negative numbers, as " $\mathrm{z}$ " scores do.

Exhibit 2 plots the six groups' performance on the posttest measured item tasks of primary, related and less related tasks. Critical t's were found for groups 2,3 , and 4 on the variable of learning of the primary task. On learning of the related task only groups three (3) and group four (4) had critical t values. On learning of the less related tasks only group four (4) had a critical $t$ value. (See Exhibit 2.) 


\section{Exhibit 2}

Comparison of Group Performance Scores with Normalized T-Scores Across The Three Measured Item Tasks of the Postest

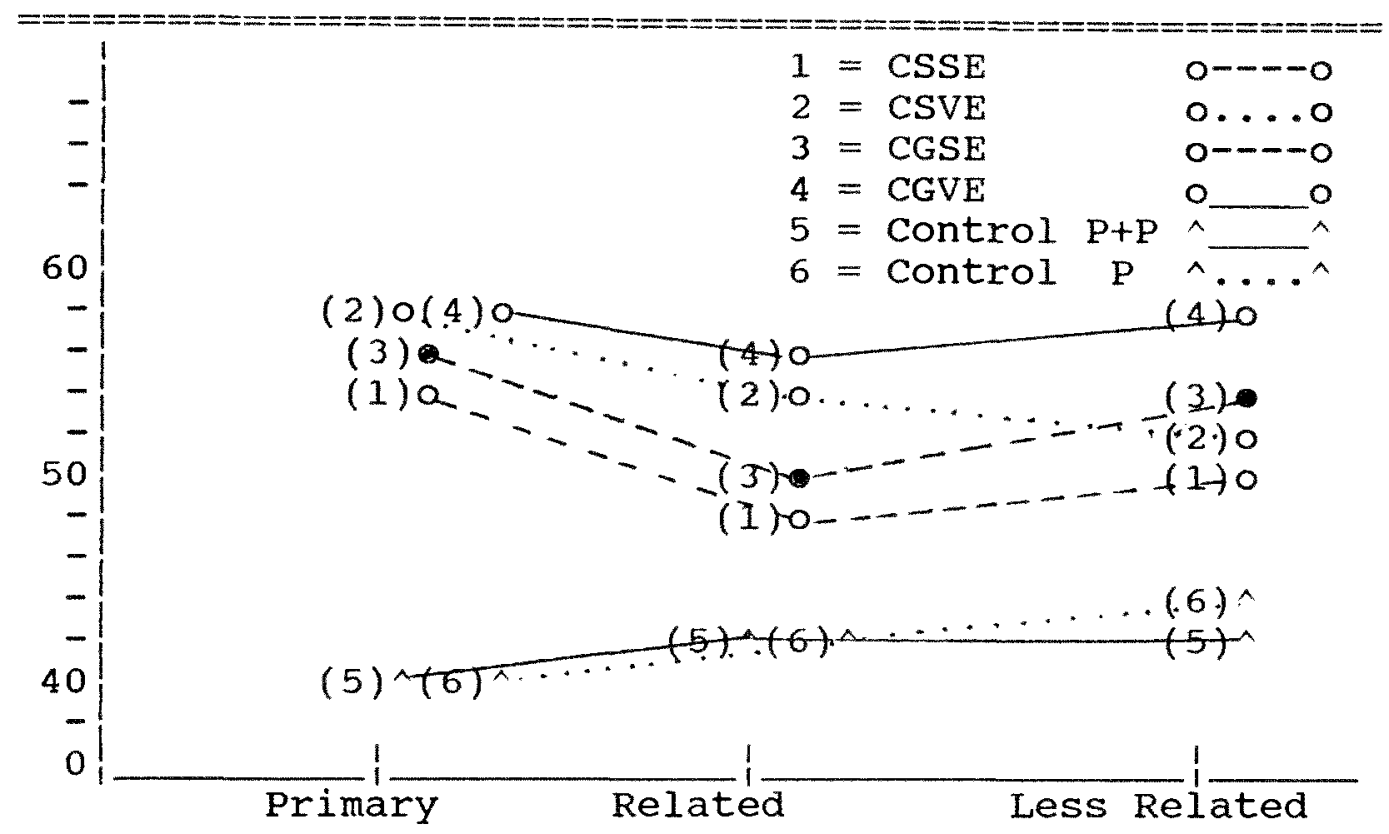

Though no critical $t$ numbers were found for group

5 and group 6 a planned comparison was conducted

between the two control groups (group 5 pretest and posttest and group 6 posttest only) to determine if there were any significant differences on the measured items of the posttest. For the primary task items the F ratio was .9819 with a significance of $F$ of .3244 . For related task items the $F$ ratio was .0540 with a significance of $F$ of .8318 . For the less related task items the $F$ ratio was 1.4408 with a significance of $F$ of .2332 . Neither of the two groups was significantly different on any of the measured item tasks. 


\section{Summary}

This chapter presented the findings of the analysis procedures run on the collected data from the sample on the pretest and posttest measured items of primary, related, and less related tasks. The sample population was identified and described in detail. The analysis procedures were described and the results of the findings presented in seven tables and one exhibit. Seven null hypotheses generated in chapter one were tested and analyzed.

The first null hypothesis was tested and the findings support the rejection of the null hypothesis that there would be no significant differences between content general learning strategies and content specific learning strategies on the measured item tasks of the posttest.

The second null hypothesis was tested and the findings support the rejection of the null hypothesis that there would be no significant differences between visual and semantic encoding and semantic only encoding on the measured item tasks of the posttest.

The third null hypothesis was tested and the findings support the rejection of the null hypothesis that there would be no significant differences between 
related task learning and less related task learning on the measured item tasks of the posttest.

The fourth null hypothesis was tested and the findings support the rejection of the null hypothesis that there would be no significant differences on the posttest measured item tasks due to the independent variable of level of education.

The fifth null hypothesis was tested and the findings support the rejection of the null hypothesis that there would be no significant differences on the posttest measured item tasks due to the independent variable of years of experience as a teller.

The sixth null hypothesis was tested and the findings failed to support the rejection of the null hypothesis that there would be no significant differences due to the independent variable of related experiences.

The seventh null hypothesis was tested and the findings failed to support the rejection of the null hypothesis that there would be no significant differences due to the independent variable of prior training in detection of counterfeit currency.

The results of the data indicate that there is a need for the acquisition of a learning strategy by learners to enhance their ability to transfer learned material to new tasks which may be required of them. 
The results also reflect that a visual and semantic approach leads to more effective recall and retention of the learned material. The visual and semantic approach enables the learner to transfer learning more effectively than does the semantic only approach. This would indicate, as a number of researchers have reported, (Hunt, 1978; Klatzky and Stoy, 1978; Sless, 1981; Sternberg, 1985; Kosslyn, 1981 and 1985) visual enhancement to semantic encoding leads to a "deeper coding" of the learned material. 
CHAPTER V

SUMMARY, CONCLUSIONS, RETROSPECT, AND RECOMMENDATIONS

\section{Summary}

This study compared two learning strategy treatment effects, content specific learning with content general learning, across two methods of information processing or encoding. The two methods of encoding learned material compared were: (1) semantic only encoding and (2) visual and semantic encoding. The purpose of the study was to determine if learning strategies obtained during the content general treatments could enable the subjects to transfer learning of cognitive skills from primary tasks to related tasks and to less related tasks, and if so, do this more effectively than the content specific learning. The study included a comparative analysis of the performance of a random sample of tellers $(N=300)$ from participating banking establishments located throughout Broward and Dade counties, Florida.

Seven null hypotheses were generated and tested to determine the statistical significance of the differences between the mean scores obtained. The analysis of covariance was the statistical procedure used to test the significance at the $p<.05$ level of 
alpha with one degree of freedom: df $=1$. A paired $t$-test was conducted on the sample $(N=300)$ for the related task items to the less related task items.

The analysis of mean scores showed the following:

1. The primary task scores achieved by the tellers in the study's four treatment groups were not significantly different across treatments but were significantly different across methodologies (Table 2 and Table 4).

2. The mean scores achieved by the four treatment groups on the related task scores were significantly different for the content general groups over the content specific groups (Table 2 and Table 3 ).

3. The mean scores achieved by the four treatment groups on the less related task scores from the posttest revealed that the group 4 content general with visual and semantic encoding (CGVE) was significantIy different than all other groups (Table 2).

4. The mean scores achieved by the visual and semantic encoding groups were significantly different than the scores achieved by the semantic only encoding groups on all three measured tasks of primary, related and less related tasks (Table 4 ).

5. The random samples' mean scores obtained on related tasks were significantly different than mean scores obtained on less related tasks (Table 5). 
6. The mean scores of subjects from the random sample having experience as a teller on the primary, related, and less related tasks were significantly different than those subjects not having had previous experience as a teller (Table 6). (The cut off point was apparently two years experience.)

7. The mean scores obtained by subjects having higher levels of education were significantly different than the scores obtained by subjects with lower levels of education on the measured items of primary and related tasks. However, on the measured items of less related tasks there were no significant differences noted. This indicates that though the level of education can influence learning of primary and related matter it does not necessarily effect the transfer of learning, especially to less related tasks (Table 6 and Table 7).

8. The mean scores obtained by subjects who had prior related experiences as either retail cashiers or work in financial organizations did not significantly differ from those subjects who did not have prior related experience on the posttest measured items of primary, related, and less related tasks (Table 7).

9. The mean scores for those subjects having previous training in detection of counterfeit currency were greater but not significantly different than 
subjects not having previous training in detection of counterfeit currency on the primary, related, and less related tasks (Table 7 ).

\section{Conclusions}

The findings of this study justify the following conclusions applicable to the population of this study:

1. The major question this study was designed to answer: What is the comparative effectiveness of content general learning over content specific learning in regards to transfer of learning? On the basis of the data reported in this study, the conclusion drawn is that, with the possible exception of the primary task, content general learning groups performed more effectively in transferring learning to related and less related tasks than the content specific learning groups.

2. Visual and semantic encoding groups outperformed semantic only encoding groups in both learning of the primary task and transfer of learning to related and less related tasks, no matter whether it was content general learning or content specific learning.

3. There was a significant difference in performance by subjects for related tasks over less 
related tasks, supporting a hypothesis formulated by Duncan (1958).

4. Significant differences in performance in the transfer of learning were noted for the independent variable of experience supporting the conclusion that: subjects with more than two years prior training as a teller significantly outperformed subjects with no previous experience as a teller on primary and less related tasks, indicating that experience aided transfer of learning (Rogoff and Gauvain, 1984).

5. There was a significant difference for the variable of level of education on the performance of tellers on the posttest's measured items of primary and related tasks. The difference was reflected in the scores of those tellers with four (4) years of college over subjects with only twelve years of school; however, there was no significant difference noted for the less related task items. The lack of significance in the less related task items indicates that a subject's level of education does not necessarily effect their ability to transfer learning.

6. Subjects with related experiences such as working as a retail cashier or in a financial organization prior to working as a teller performed more efficiently, but did not differ significantly from 
tellers with no prior related experiences in the transfer of learning.

7. Subjects with previous training in the detection of counterfeit currency outperformed subjects with no prior training on the primary task but did not differ significantly on any of the measured item tasks.

In summary, the following generalizations appear to be applicable to learning cognitive tasks similar to those used in this study: (a) If initial learning is solely for the purpose of performing that task, a specific method of learning is the most efficient from a learning time factor. (b) Upon the learning of the initial task, the learning of a related task is enhanced when a general learning strategy is applied by the learner (such as one that requires problem solving or personalization of the task to be learned). (c) The transfer of learning to less related tasks is best accomplished through the use of general learning strategies which use personalization of the learning effort. (d) Learning can be transferred to related tasks more effectively than to less related tasks regardless of the learning strategy used, though general learning strategies do outperform specific strategies. 


\section{Retrospect}

In retrospect, a number of unexpected limitations to this study arose from the dictates of sample size, time factors, and manpower needs of the participating organizations. First, in order to properly analyze the collected data in this study, a certain sample size was needed to maintain power at .80 with a significance level of alpha at $p<.05$. This called for 33 subjects per cell, for six cells, per Cohen (1977, p. 384). To obtain this number of tellers the experimenter had to enlist the cooperation of a number of banking establishments throughout Broward and Dade counties, Florida.

The allotted time for training due to restraints imposed by the banking establishments limited the amount of preparation subjects could use to develop a learning strategy. Due to time restraints materials such as Gugliomeno's "Self Directed Learning" and Colb's "Learning style Inventory" could not be presented. Training sessions were limited to a three hour time span. Also many of the banking establishments found it difficult to excuse enough tellers at any one time to significantly increase the sample size with any single training session. 
The experimenter had requested that each bank give at least twenty (20) tellers per session. In actuality the experimenter trained anywhere from six (6) to twenty-nine (29) subjects at one time. Another limitation, which was discovered, was that the experimenter, who also did the training, became more proficient in his presentation as time passed. This might have effected later groups in their learning ability. As Brookfield (1986) pointed out the more effective a trainer becomes the better the performance of the participating learners. To offset this effect all groups had equal opportunity to receive training at any stage in the study, through the randomization of the lesson plans to the groups.

\section{Recommendations}

A number of implications for the practitioner are indicated by this study. A major practical implication which can be drawn from this study is the importance of specifying the objective in learning new tasks or materials. If the purpose of the learning is to perform a particular task and only that task, the content specific approach would seem to be the most efficient. However, if the purpose of the learning is to make applications to the solution of related and less related problems, the lesson plans should involve 
an approach which includes a method to enable the learner to develop a learning strategy which personalizes the learned material, such as was represented by the content general learning strategy introduced in this study.

A second major implication for the practitioner is that visual and semantic encoding of learned information leads to a deeper encoding of the learned material. This enables the subject a more efficient recall and retention of the material. This would appear to imply that lectures should be enhanced with visual aids for the learners.

Though this study was conducted within the controlled environment of the training centers of the participating banking establishments, it is believed that any learning achieved by the subjects was generalized to "real life" learning. The subjects" performance on the measured items of the posttest meets the parameters established from related literature. In this same line of thought, future research should consider a longitudinal study of teller's performance after receiving the training used throughout this study. A final recommendation is for future researchers to allow more time for the subjects to develop a learning strategy prior to the training of the primary, related and less related tasks. 


\section{LIST OF APPENDICES}

Appendix

Title

Page

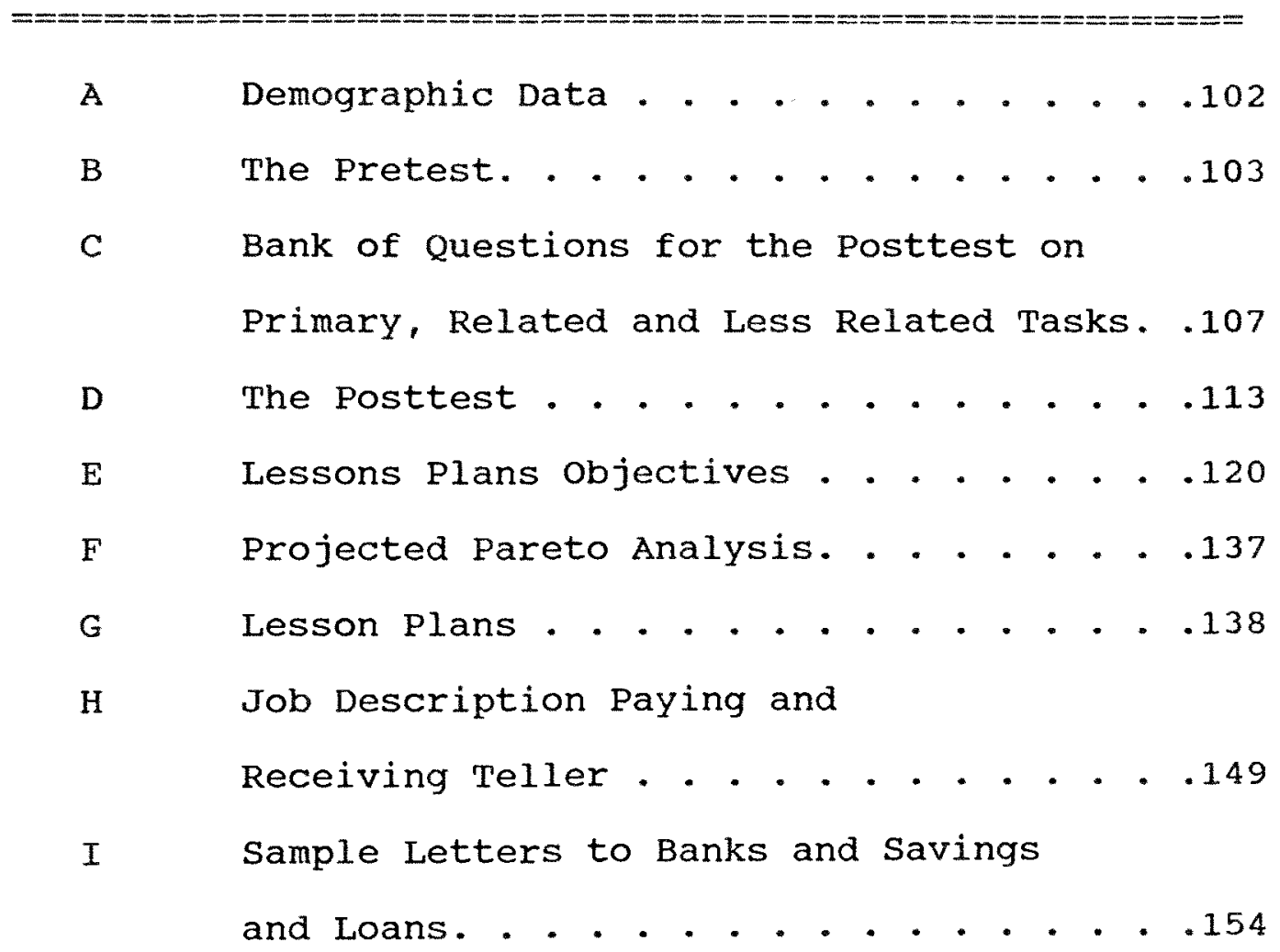


APPENDIX A

Demographic Data

Directions: Please fill out the following personal information sheet. All data obtained here are confidential and will not be released. The sole purpose is for statistical analysis. Place your name, date of birth, and the ID number assigned to you on the answer sheet. For questions 1-6 fill in the circle on the answer sheet that most clearly identifies your situation.

01. Please check the group nearest your years of experience as a teller.

1. (Less than < 6 months)

2. (Greater than $>6$ months but $<2$ years)

3. (Greater than $>2$ yrs but $<5$ yrs)

4. (over 5 years)

02. Native Language:

1. (Spanish)

2. (English)

3. (French)

4. (Haitian)

5. (German)

6. (Italian)

7. (other)

03. Prior training or experiences with counterfeit money?

1. Yes 2. No

04. Marital Status:

1. Single

2. Widowed

3. Divorced

4. Married

05. Ethnic Background:

1. Caucasian

2. Asian American

3. American Indian

4. Black

5. Hispanic

06. Related experiences in handling monetary obligations?

1. Retail Cashier

2. Financial organization

3. other

4. None 


\section{APPENDIX B \\ THE PRETEST}

Directions: The following is a multiple choice test. Please select the answer that most clearly answers the question. Do not mark the question form, mark your answers on the answer sheet by filling in completely the circle corresponding to the number of the answer you wish to choose. Questions:

07. What is counterfeit currency?

(1) stolen currency,

(2) money not printed by legal authority,

(3) money printed outside the U.S. Mint,

(4) money without red and blue fibers.

08. What is Intaglio printing?

(1) use of depressed surface on a plate to create a build up of ink on paper.

(2) use of an offset press to print counterfeit.

(3) use of a light sensitive tin to eke plates

(4) None of the above. 08

09. Serial numbers can be changed on counterfeit notes by:

(1) printing a new serial number for each note.

(2) use of a hand counter to change the numbers after the note has been printed.

(3) leaving the serial number off of the original plate and adding them with a second run on the offset press.

(4) none of the above.

09

10. Paper currency can only have genuine red and blue fibers in it:

(1) if they use the same type of paper as the government uses and print counterfeit currency on that paper.

(2) if red and blue fibers were drawn on with colored ink pens.

(3) if the paper was produced at the control plant and had the threat type fibers added when it was being made.

(4) None of the above. 
11. The first letter in the serial number corresponds to?

(1) the position of the bill on printing sheet.

(2) A coded letter representing the issuing Federal Reserve Bank.

(3) A random letter assignment with no significance.

(4) A Treasury Department auditing code.

12. The denomination most frequently counterfeited:
(1) $\$ 10.00$
(2) $\$ 20.00$
(3) $\$ 50.00$,
(4) $\$ 100.00$

13. The correct form to complete when a counterfeit note has been received is a:
(1) SSF 1233
(2) SSF 1604
(3) Bank audit form 105
(4) IRS 1044

14. To verify if a note is genuine you may:

(1) ask the customer presenting the note

(2) call the police

(3) call the U. S. Secret Service

(4) call the Federal Bureau of Investigations 14

15. The check letter on U. S. currency is located:

(1) on the back of the bill, lower right.

(2) on the back of the bill, upper left.

(3) on the front of the bill, over the portrait.

(4) on the front of the bill, lower right. is

16. Most counterfeits are produced by:

(1) using engraved plates.

(2) the intaglio process.

(3) offset press method.

(4) xeroxed copying.

17. A Federal Reserve note that states "In God we Trust" on the back of the note is:

(1) is genuine

(2) is counterfeit

(3) could be genuine or counterfeit, as some series of notes have this printed on them and other series don't.

(4) none of the above. 
18. One way to spot a counterfeit note is to check the Treasury seal:

(1) for evenness of the points on the exterior of the seal.

(2) to see if the note has a key and a balance.

(3) for the words U. S. Treasury.

(4) to see if the printing date is featured. xa

19. A quick procedure to check for counterfeit is to:

(1) inspect the portrait and the background around it for clarity and evenness.

(2) snap the bill with your hands to see if it tears.

(3) hold the note up to the light and see if you can find the watermark.

(4) rub the currency on a clean sheet of paper to see if it smudges.

20. The quadrant number on a Federal Reserve Note appears in which corner:

(1) the lower left rear corner of the note.

(2) the upper left front corner of the note.

(3) over the portrait of the President.

(4) the middle of the rear of the note.

21. To the right of the portrait, is the Federal Reserve Seal, the letter appearing in the center:

(1) corresponds to the issuing FRB.

(2) corresponds to the series year of the note.

(3) stands for the check letter of the note.

(4) is a placement mark relating to the position of the currency during printing.

22. A star following some serial numbers symbolizes:

(1) that the note is a replacement note for one that did not pass inspection.

(2) that the note was a collector's item.

(3) that the original number had been detected on a counterfeit bill.

(4) nothing, there is no significance. 22

23. The difference between silver certificate and Federal Reserve Note are:

(1) the silver certificate has a blue seal and is no longer printed.

(2) nothing, there is no difference.

(3) the silver certificate has a silver seal.

(4) the Federal Reserve Note is backed up by a gold deposit. 
24. The four enlarged numbers appearing within the scroll work of the face of the note correspond to the:

(1) year of issue

(2) letter appearing in the center of the FRB seal.

(3) The check letter.

(4) The President appearing in the portrait. 24

25. A Federal Reserve note has:
(1) a blue seal
(2) a green seal
(3) a gold seal
(4) a red seal.

26. An offset counterfeit note produced from a photograph of a genuine bill has many of the same characteristics of the genuine, except:

(1) the serial number.

(2) the correct color green in of genuine.

(3) there are no red and blue fibers in paper.

(4) a correctly reproduced Treasury seal. 26

27. To detect a "Bleached " bill (usually genuine one dollar FRB notes, bleached to take out the ink, but keep in the fibers,) one can do several things, such as:
(1) hold the note up to the light to see if the one dollar imprint is still visible.
(2) check to see if red and blue fibers appear to be bleached.
(3) check the texture of the paper.
(4) all of the above.
27

28. If you receive a counterfeit note from a customer you should:

(1) notify your supervisor.

(2) give the note to the next customer.

(3) return the note to the customer who presented it.

(4) none of the above. 


\section{APPENDIX C}

Bank of Questions for the posttest on Primary, Related and Less Related Tasks

01. Altered Federal Reserve notes are known as the "poor man's counterfeit." They are produced by:

(1) altering one genuine FRB note.

(2) altering two genuine FRB notes and affixing the ends on a lower denomination note.

(3) printing them on an offset press.

(4) all of the above.

02. A "tape job" refers to:

(1) running a recorded scam operation.

(2) taping two bills together at the portrait.

(3) taping two ends of higher denomination notes onto a lower denomination note.

(4) none of the above.

03. Altered currency can not be successfully passed if:

(1) the teller counts each note as they are received.

(2) the teller stacks the currency to check for evenness of the edges of the notes.

(3) the teller checks to make sure the number written under the portrait is the same as the denomination number appearing in the corner of the note.

(4) the teller checks the treasury seal.

04. An easy procedure to detect an altered note is to:

(1) turn the note on to the reverse side and see if it reads ONE in the middle of the note.

(2) see if Washington's portrait is on a higher denomination note.

(3) check to see if the ends have been pasted or taped onto the note.

(4) all of the above. 
05. Altering money is:

(1) a misdemeanor crime compared to counterfeiting which is a felony.

(2) used when crime organizations want to hide the source of their funds.

(3) a felony and carries the same penalties as does counterfeiting.

(4) not a federal crime but a state violation.

06. Altered currency:

(1) always has the same serial number.

(2) is always a one dollar note raised to a higher denomination.

(3) is made with very cheap paper and is easily detected.

(4) can be any denomination raised to a higher denomination.

07. When handling an altered note a teller should always:

(1) try to put it in an envelope to preserve any fingerprints on the tape or glue used on the altered ends.

(2) notify security and show the note to all the tellers to alert them to the passing of the item.

(3) put the note into the cash drawer and make a note of it before closing.

(4) give the note back to the customer and ask for a genuine note.

08. An altered note can be detected by:

(1) checking the evenness of the points in the U.S. Treasury seal.

(2) the clarity of the portrait.

(3) the series year of the note.

(4) checking the ends of the note to see if they have been pasted or taped on to the note.

09. An altered U. S. FRB note can be detected by:

(1) checking the date on the note.

(2) checking the serial number and calling the Secret Service for verification.

(3) checking to see if the bill is made by the intaglio process.

(4) None of the above. 
10. "Raised notes" are:

(1) genuine U. S. currency notes altered to reflect a higher denomination.

(2) made on offset presses.

(3) usually made from foreign currency.

(4) xeroxed from genuine currency.

11. When accepting a U.S. Treasury check you must always:

(1) ask for two pieces of identification.

(2) request the person repeat verbatim their social security number.

(3) make sure that the presenter is at least related to the payee.

(4) ask them what kind of car they are driving.

12. By verifying an account for someone cashing a U. S. Treasury check.

(1) it allows the teller to see if the person has enough money in the account to cover the check.

(2) it determines if the presenter even has a valid account.

(3) it ensures that the presenter of the check spells or signs their name the same as the account holder.

(4) none of the above.

13. Forged U. S. Treasury checks will be returned to the bank :

(1) immediately

(2) within one month

(3) within 6-8 months

(4) never, because the U.S. Treasury backs up the checks.

14. Banking policy is:

(1) to always accept U. S. Treasury checks from customers as well as noncustomers.

(2) to hold all U. S. Treasury checks.

(3) to never cash U. S. Treasury checks.

(4) to accept and negotiate U. S. Treasury checks for customers of our bank.

15. Forgers:

(1) are always nervous when they are attempting to negotiate a check.

(2) can be easily detected by the way they act or dress. 
(3) are usually cool and friendly when passing a forged check to a teller.

(4) are intimidated easily and will admit their guilt if confronted.

16. A common time for forgers to attempt negotiation of checks is:

(1) early in the morning right after opening.

(2) lunch time.

(3) just before closing time.

(4) whenever the teller looks like they are very busy or has a long line of customers.

17. A primary piece of identification for cashing a check is:

(1) a social security card.

(2) a voter's registration form.

(3) any photo ID card.

(4) a driver's license with a photograph

18. A family member can cash a Social security check for a deceased payee.

(1) as long as they have the same last name.

(2) if they are the spouse of the deceased payee.

(3) if they are listed on the same account as the deceased payee.

(4) none of the above.

19. One thing to remember when cashing a U. S.Treasury checks is:

(1) check to see if the amount is under $\$ 500.00$.

(2) check to see if it is a split deposit and if so look more closely.

(3) always make the presenter sign the check in my presence.

(4) be courteous and make sure to give the correct change.

20. The bank is not responsible for cashing a forged U. S. Treasury check.

(1) if the payee endorsed the check and then had someone else cash it for him.

(2) if the presenter had proper identification when cashing the check.

(3) if the presenter has a valid account with the bank.

(4) if ihe check is under $\$ 1000.00$. 
21. The correct procedure for a teller to follow when confronted with a suspected forgery is:

(1) contact the supervisory teller

(2) stall the presenter while an attempt is made to contact the payee.

(3) notify security.

(4) all of the above.

22. The most common forms of counterfeited identification used when cashing forged checks are:

(1) driver's licenses

(2) social security cards.

(3) state identification cards.

(4) credit cards.

23. A legitimate bank customer:

(1) wouldn't knowingly put forged U. S. Treasury checks into their accounts.

(2) could knowingly put the forged Treasury checks in their account to acquire the interest on the checks prior to government detection.

(3) would be afraid of getting caught handling forged checks.

(4) would alert the bank if they suspected they had a forged U. S. Treasury check.

24. A wife can sign for her husband on a U.S. Treasury check:

(1) any time if there are children involved.

(2) as long as she has done so in the past and still has his permission to sign his name.

(3) up until the couple are legally divorced.

(4) none of the above.

25. Getting a negotiator's license tag number can:

(1) help identify the presenter of a check by getting the name of the auto's owner.

(2) find out if they drive a classy car.

(3) see if they are from out of state.

(4) let authorities know if there were other people in the car at the time of the crime. 
26. Forgeries can occur in which of the following schemes:

(1) child of payee cashes the check.

(2) account holder cashes a third party U. S. Treasury check.

(3) a check is used to open an account with fraudulent Identification.

(4) all of the above.

27. Store owner's deposits containing U. S. Treasury checks:

(1) never need to be checked because the store would lose money when it was reclaimed.

(2) don't need to be checked because the business would stand behind the loss.

(3) Could contain forged checks that the owner may or may not know are stolen or forged.

(4) rarely cause banks any problems.

28. When a forged U. S. Treasury check is detected a bank should contact which agency to investigate the case:

(1) Federal Bureau of Investigations.

(2) U. S. Treasury Internal Revenue Service.

(3) U. S. Customs.

(4) U. S. Secret Service.

29. The new paper checks issued by the U. S. Treasury Department have helped:

(1) eliminate most of the forgeries.

(2) reduced the cost to the U.S. government for making the checks.

(3) made it more difficult to duplicate the checks.

(4) made it easier for forgers to forge U. S. Treasury checks.

30. U. S. Treasury checks can be:

(1) income tax return checks.

(2) supplemental security income (SSI).

(3) social security checks.

(4) all of the above. 


\section{APPENDIX D}

\section{THE POSTTEST}

(Test of General Knowledge Relating to Counterfeit Currency, Altered U. S. Currency and Forged U. S. Treasury Checks)

Directions: All data obtained here are confidential and will not be released. The sole purpose is for statistical analysis. Please place your name, date of birth, and the ID number assigned to you on the answer sheet. For questions $1-6 \mathrm{fill}$ in the circle on the answer sheet that most clearly identifies your situation.

01. Please check the group nearest your years of experience as a teller.

1. (Less than $<6$ months)

2. (Greater than $>6$ months but

less than $<2$ years)

3. (Greater than $>2$ yrs but $<5$ yrs)

4. (over 5 years)

02. Native Language:

1. (Spanish)

2. (English)

3. (French)

4. (Haitian)

5. (German)

6. (Italian)

7. (other)

03. Prior training or experiences with counterfeit money?

1. Yes 2. NO

04. Marital status:

1. Single

2. Widowed

3. Divorced

4. Married

05. Ethnic Background:

1. Caucasian

2. Asian American

3. American Indian

4. Black

5. Hispanic 
06. Related experiences in handling monetary obligations?

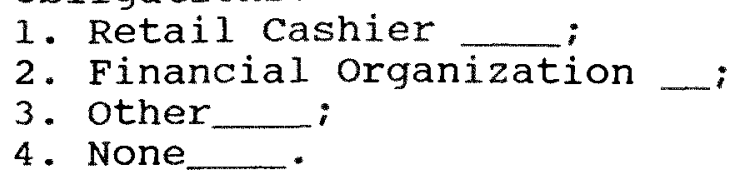

07. What is counterfeit currency?
(1) stolen currency,
(2) money not printed by legal authority,
(3) money printed outside the U.S. Mint,
(4) money without red and blue fibers.

08. Serial numbers can be changed on counterfeit notes by:

(1) printing a new serial number for each note.

(2) use of a hand counter to change the numbers after

the note had been printed.

(3) leaving the serial number off of the original plate and adding them with a second run on the offset press.

(4) None of the above

09. The first letter in the serial number corresponds to?

(1) the position of the bill on printing sheet.

(2) the issuing Federal Reserve Bank.

(3) a random letter assignment with no significance.

(4) a Treasury Department auditing code.

10. The denomination most frequently counterfeited:
(1) $\$ 10.00$,
(2) $\$ 20.00$,
(3) $\$ 50.00$,
(4) $\$ 100.00$.

11. The check letter on U. S. currency is located:

(1) on the back of the bill, lower right.

(2) on the back of the bill, upper left.

(3) on the front of the bill, upper left.

(4) on the front of the bill, lower right. $x_{1}$

12. Most counterfeits are produced by:
(1) using engraved plates.
(2) the intaglio process.
(3) offset press method.
(4) xeroxed copying. 
13. A quick procedure to check for counterfeit is to:

(1) inspect the portrait and the background around it for clarity and evenness.

(2) snap the bill with your hands to see if it tears.

(3) hold the note up to the light and see if you can $f$ ind the watermark.

(4) rub the currency on a clean sheet of paper to see if it smudges.

14. To the right of the portrait, is the Federal

Reserve Seal, the letter appearing in the center:

(1) corresponds to the issuing FRB.

(2) corresponds to the series year of the note.

(3) stands for the check letter of the note.

(4) is a placement mark relating to the position of the currency during printing.

15. A United States note has:
(1) a blue seal.
(2) a green seal.
(3) a gold seal.
(4) a red seal.

16. If you receive a counterfeit note from a customer you should:

(1) notify your supervisor

(2) give the note to the next customer

(3) return the note to the customer who presented it

(4) none of the above.

16

17. Altered Federal Reserve notes are known as the "poor man's counterfeit." They are produced by:

(1) altering one genuine FRB note.

(2) altering two genuine FRB notes and affixing the ends on a lower denomination note.

(3) printing them on an offset press.

(4) all of the above.

17

18. A "tape job" refers to:

(1) running a recorded scam operation.

(2) taping two bills together at the portrait.

(3) taping two ends of higher denomination notes onto a lower denomination note.

(4) none of the above. 
19. Altered currency can not be successfully passed if:

(1) the teller counts each note as they are received.

(2) the teller stacks the currency to check for evenness of the edges of the notes.

(3) the teller checks to make sure the number written under the portrait is the same as the denomination number appearing in the corner of the note.

(4) the teller checks the treasury seal. 19

20. An easy procedure to detect an altered note is to:

(1) turn the note on to the reverse side and see if it reads ONE in the middle of the note.

(2) see if Washington's portrait is on a higher denomination note.

(3) check to see if the ends have been pasted or taped onto the note.

(4) all of the above.

20

21. Altering money is:

(1) a misdemeanor crime compared to counterfeiting which is a felony.

(2) used when crime organizations want to hide the source of their funds.

(3) a felony and carries the same penalties as does counterfeiting.

(4) not a federal crime but a state violation.21

22. Altered currency:

(1) always has the same serial number.

(2) is always a one dollar note raised to a higher denomination.

(3) is made with very cheap paper and is easily detected.

(4) can be any denomination raised to a higher denomination.

23. When handling an altered note a teller should always:

(1) try to put it in an envelope to preserve any fingerprints on the tape or glue used on the altered ends.

(2) notify security and show the note to all the tellers to alert them to the passing of the item.

(3) put the note into the cash drawer and make a note of it before closing.

(4) give the note back to the customer and ask for a genuine note. 
24. An altered note can be detected by:

(1) checking the evenness of the points in the U. S. Treasury seal.

(2) the clarity of the portrait.

(3) the series year of the note.

(4) checking the ends of the note to see if they have been pasted or taped on to the note. 24

25. An altered U. S. FRB note can be detected by:

(1) checking the date on the note.

(2) checking the serial number and calling the secret Service for verification.

(3) checking to see if the bill is made by the intaglio process.

(4) None of the above.

26. "Raised notes" are:

(1) genuine U. S. currency notes altered to reflect a higher denomination.

(2) made on offset presses.

(3) usually made from foreign currency.

(4) xeroxed from genuine currency.

27. When accepting a U. S. Treasury check you must always:

(1) ask for two pieces of identification.

(2) request the person repeat verbatim their social security number.

(3) make sure that the presenter is at least related to the payee.

(4) ask them what kind of car they are driving.

28. Forged U. S. Treasury checks will be returned to the bank :

(1) immediately

(2) within one month

(3) within 6-8 months

(4) never, because the U. S. Treasury backs up the checks.

29. Banking policy is:

(1) to always accept U. S. Treasury checks from customers as well as noncustomers.

(2) to hold all U. S. Treasury checks.

(3) to never cash U. S. Treasury checks.

(4) to accept and negotiate U. S. Treasury checks for customers of our bank. 
30. Forgers:

(1) are always nervous when they are attempting to negotiate a check.

(2) can be easily detected by the way they act or dress.

(3) are usually cool and friendly when passing a forged check to a teller.

(4) can be intimidated easily and will admit their guilt if confronted.

31. A family member can cash a social security check for a deceased payee.

(1) as long as they have the same last name.

(2) if they are the spouse of the deceased payee.

(3) if they are listed on the same account as the deceased payee.

(4) none of the above.

31

32. The correct procedure for a teller to follow when confronted with a suspected forgery is:

(1) contact the supervisory teller

(2) stall the presenter while an attempt is made to contact the payee.

(3) notify security.

(4) all of the above.

33. The most common forms of counterfeited identification used when cashing forged checks are:

(1) driver's licenses

(2) social security cards.

(3) state identification cards.

(4) credit cards.

34. Getting a negotiator's license tag number can:

(1) help identify the presenter of a check by getting the name of the auto's owner.

(2) find out if they drive a classy car.

(3) see if they are from out of state.

(4) let authorities know if there were other people in the car at the time of the crime. 
35. Forgeries can occur in which of the following schemes:

(1) child of payee cashes the check.

(2) account holder cashes a third party U. S. Treasury check.

(3) a check is used to open an account with fraudulent identification.

(4) all of the above.

36. When a forged U. S. Treasury check is detected a bank should contact which agency to investigate the case:

(1) Federal Bureau of Investigations.

(2) U. S. Treasury Internal Revenue Service.

(3) U. S. Customs.

(4) U. S. Secret Service. 


\section{APPENDIX E}

\section{LESSON PLAN OBJECTIVES}

This study focuses on several aspects of learning relevant to the teller training regarding identification and handling of counterfeit currency and handling of forged U.S. government checks. The instruction was given by a special Agent of the U. S. secret Service (USSS). The USSS is charged with the criminal investigative responsibilities for counterfeit money, forged U.S. government checks and bonds, computer fraud, credit card fraud as well as any violation against the financial obligations of the U. S. government.

The data presented here were gathered through the use of several techniques. The first was a modified delphi technique, known as the "crawford slip", which included two bank supervisors, two USSS Agent supervisors (SME'S), two bank trainers (less than two years on the job), and a senior special agent (eighteen years on the job). The second technique was a "green light" discussion session with a bank officer (Senior Vice President/ Operations), a bank training officer, a supervisory special agent of the USSS and a senior special agent. 
The following are some of the more priority type training problems that were identified as existing in the work place. A more complete list of those problems identified through these techniques has been omitted due to space and relevancy to this study.

1. Teller's need to identify and distinguish counterfeit currency from genuine currency.

2. Teller's need to properly handle (according to both bank administration and U.S. government regulations) counterfeit currency once it is detected.

3. Teller's need to recognize habits of individual's presenting counterfeit currency or forged checks.

4. Teller's need to identify and distinguish altered U. S. currency from genuine unaltered U. S. currency. 5. Teller's need to identify fraudulent activity being perpetrated on their banks.

Only number one (1) and number two (2) which were related were chosen to be identified for treatment intervention in the form of course study. Number three (3) and number four (4) were selected to be measured to see if the training given on the first task transferred to the other tasks. 


\section{JOB ANALYSIS}

(Enabling objectives)

To understand the job related to the priority problem a review of the job description of a bank teller, written by the senior vice President of operations for one of the participating banks, has been included. (See Appendix H.) The four major responsibilities of a teller are: (1) Accepting and processing currency, coins, checks, and other financial obligations which depositors tender for credit to their demand or time deposit account (s); (2) Accepting and processing bond coupons, food stamps, Visa/Mastercard and American Express merchant deposits for credit by bank depositors and bank charge card payments;

(3) Cashing savings withdrawals for depositors;

(4) Exchanging checks drawn on the bank or other banks for currency payable to an individual when: a. check(s) are in proper order; $b$. check $(s)$ are presented by $a$ customer or person properly identified and known to the bank as having the right title and interest in the check (s); c. check (s) are within teller check cashing limits.

Specific human relations skills in their job description state that tellers should have: 1. contact 
with customers - teller should smile, use the customer's name, greet the customer, be aware of the proper time to cross-sell a bank service, and close the transaction pleasantly, thanking the customer for their business. 2. Teller should treat co-workers with the same consideration and respect he/she would like to receive. 3. Teller should display the same consideration and respect to co-workers in other departments. 4. Tellers may provide guidance to an assigned teller trainee for a specified period of time. 5. Teller works under direct supervision according to policies and procedures set by senior management. Teller should refer exceptions of policy and procedure to their supervisor for approval.

Specific job duties gleaned from the job description state:

1. Prior to opening for business tellers should be: a. turning on the teller machine and checking to be sure it registers the correct date and machine number;

b. setting date stamp(s) with current date, when applicable;

c. seeing that a sufficient supply of forms are available to handle the day's transactions; d. removing currency and coin from the assigned 
compartment in the vault and placing it in the station compartment, being certain currency and coin, in sufficient denominations and quantity, are available to handle the current day's business.

2. Transacting the day's business:

a. verifying, by counting, the amount of currency and coin tendered in a deposit;

b. Reviewing checks tendered for deposit to be certain they meet the requirements of negotiability, that is: 1 . the instrument is drawn on a bank;2. the check is signed; 3 . date on the check ( $s$ ) is current (not postdated or stale-dated); 4. the check bears no alteration or change in date, amount, name of payee, or signature; 5 . the written and numerical amounts agree; 6 . check is endorsed as written by the person to whom the item is payable and/ or the person who is tendering the check for deposit. Checks made payable to a corporation, association, company or several people jointly should not be accepted for deposit into an individual account without proper authorization and approval. c. Receipting the total amount deposited by issuing a machine validation receipt to the 
depositor.

d. Accepting checks drawn on the bank tendered for exchange into currency and coin provided: 1 . the endorser is known or properly identified; 2 . the check is signed with an authorized and genuine signature; 3 . the check bears a current date; 4 . the check bears no alteration or change in date, payee, or signature; 5. the amount as written agrees with the amount as printed; there is a sufficient amount available in the account against which it is drawn to cover the amount of the check; 6. there is no stop payment order against the check.

e. Accepting checks drawn on other banks tendered for exchange into currency and coin. f. daily balancing.

\section{LEARNING OBJECTIVES}

To understand the development of learning objectives it was first necessary to specify a list of task performance objectives (TPO) for each task listed in the job related tasks of a paying and receiving teller for the function of cashing money and taking deposits from bank customers. Using the Mager 
approach each TPO statement consisted of three components including a given related to the condition of the element, a desired outcome of the given and the performance level expected.

The TPO's of the lesson plan can be seen in the following list of tasks. Each of these TPO'S will be addressed individually in the lesson plans.

Task Performance objective:

Task\# (AO1) IDENTIFYING COUNTERFEIT CURRENCY

Given the need to identify counterfeit currency and distinguish it from genuine currency being passed at the bank, a teller should be able to recognize and detect counterfeit currency when it is passed.

TaSk\# (A02) INTERVIEW PASSER AND PROPERLY HANDLE COUNTERFEIT NOTES

Given the need to maintain a chain of evidence and properly follow bank and legal guidelines, a teller should be able to recall any specific procedures and policy the bank provides for handling counterfeit notes. 
Task\# (A03) RECOGNIZE HABIT PATTERNS USED BY COUNTERFEIT PASSERS

Given the need to accept and pay out money for a banking establishment, a teller should be able to recognize habit patterns used by people attempting to pass counterfeit currency or other bogus items on the bank.

Task\# (AO4) IDENTIFY ALTERED U. S. CURRENCY Given the need for tellers to pay and receive currency for a banking establishment, a teller should be able to identify genuine currency that has been altered or raised to a higher denomination.

Task\# (A05) IDENTIFY FRAUDULENT ACTIVITIES BEING PERPETRATED ON THE BANK

Given the need to pay out and receive currency for the bank and to deal with the clientele of the bank, tellers should be able to distinguish fraudulent activities, such as forgeries or similar type activity being perpetrated on the bank.

A more thorough review of the job analysis was accomplished through the use of tasks needed to perform a certain job. These tasks were established through the use of a group discussion (Green light method) and the use of a job, duty, task questionnaire provided to 
members of the initial problem discussion group.

one of the main methodologies used to identify the various tasks associated with the jobs performed by tellers was direct observation of the tellers performing duty requirements. The following list of elements was identified as necessary to perform the task of identifying and handling counterfeit currency by a paying and receiving teller. Each of these elements will be covered in the lesson plan, however, only the first three will be measured and assessed for transfer of training by the posttest.

Exhibit E.1

\section{Task and Elements of Task}

Task Identify and handle counterfeit currency using the proper procedure.

Element A01: Observe currency being presented

Element A02: Recall identity keys of genuine currency

Element A03: Recognize and detect signs of counterfeit currency

Element A04: Identify key signs of behavior 
Element A05: Establish rapport with passer

Element A06: Inquire from passer source of cft. note

Element A07: Notify supervisory Teller of passing incident

Element A08: Initial and date cft. note and have the passer of the note also initial and date it

Element A09: Contact the U. S. Secret Service for verification

Element A10: Write up incident report for the bank records

\section{ENABLING OBJECTIVES}

To properly develop a training program that will enable bank tellers to identify, handle, and report the passing of counterfeit currency in a proper manner. To accomplish that objective a period of instruction will have to be directed toward both identifying and distinguishing counterfeit currency from genuine currency and also cover all procedures and guidelines of the banks and law enforcement on the passing of counterfeit currency. 


\section{ENABLING OBJECTIVES}

Task A: Identifying counterfeit currency

Given the passing counterfeit currency scenario establish the need for the teller to distinguish between genuine and counterfeit currency. This should require the teller to differentiate between an innocent pass by a bank customer and a knowing pass by a criminal. This portion of the class should be monitored by a bank supervisor who can assist in the critique of both the customer-teller interaction and the procedures followed.

1. Given the necessary role-player in a passing counterfeit scenario, identify if currency is counterfeit and if passing was deliberate or innocent.

2. Given the necessary role-player in a passing counterfeit scenario, the teller should obtain information pertinent to the source of the counterfeit currency.

3. Given the necessary role-players in a passing counterfeit scenario, the teller should determine the identity of the passer presenting the counterfeit note for cash. 
4. Given the necessary role-players of tellers the teller should be able to recall all proper policy and procedures for handling counterfeit currency once it has been detected. The class began with an introduction from the instructor who then presented material in a lecture format. Depending on the instructional intervention scheduled for that session, the introduction was either 10 or 15 minutes in length. The content specific learning strategy intervention followed with an introduction to the counterfeit session which lasted approximately 60 minutes. This session went over questions given to the participants to answer on the pretest-test. (It should be noted the pretest-test was given a day or two prior to the instructional intervention by the regular course instructor. The instructor was advised not to give any assistance to the teller trainees on any aspect of the test other than how to fill out the bubble in answer sheets and to correlate the questions with the correct line of the answer sheet. The instructor made no comments on the pretest-test.)

The passing out of genuine and counterfeit currency for inspection and comparison depended on whether the method being used for the given session 
was visual and semantic or semantic only encoding. If it was semantic only encoding than the instructor lectured on the key identity points of genuine currency and the types of genuine notes in circulation without visual enhancement. The lecture also covered information relating to the type of paper that genuine money is printed on to aid the teller in being able to distinguish counterfeit currency from genuine. This was followed by a 10 minute coffee break. A brief lecture on the history of counterfeit money and its origins assisted tellers in learning both sources and laws applicable to enforcement procedures to control the flow of counterfeit currency. Each of the four different treatment groups received a video presentation on "know your money." ( A visual presentation on what to look for when verifying currency.) The class concluded with a discussion on counterfeit currency and a class critique of the session.

The other three treatment groups had the same basic leaning objectives as the first, which was, the detection of counterfeit currency. Exhibit E. 3 reflects the specific "differentia" across the four treatments in a Table form. This allows the reader a more vivid picture of the nature and extent of 
variation across the treatments.

Exhibit E.2

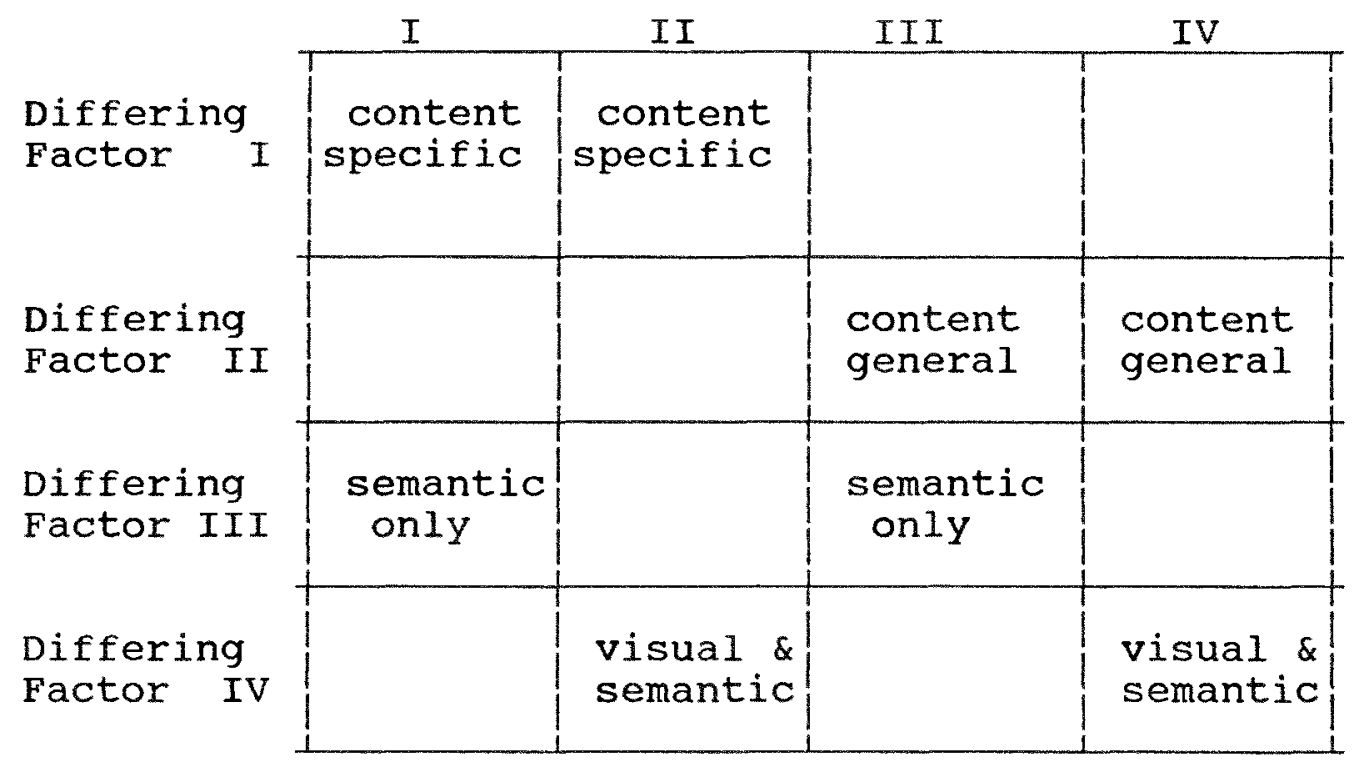

The following guides and lesson plans for the course instructor (Exhibit E.4) details the division of content into training modules for presentation. This breakdown aided in the maximization of learning efficiency and retention. 
Exhibit E. 4

\section{INSTRUCTORS GUIDE \& LESSON PLAN}

\begin{tabular}{lc} 
Bank Teller Training & Lesson Plan \# 02 \\
Ft. Lauderdale, Fla. & Page 1 of 3 \\
\hline Session: & Identifying counterfeit currency
\end{tabular}

Objective: To correctly identify and handle counterfeit currency in paying and receiving transactions

\begin{tabular}{|c|c|c|}
\hline $\begin{array}{l}\text { No. Subject } \quad \text { Tra } \\
==============\end{array}$ & ining aid & 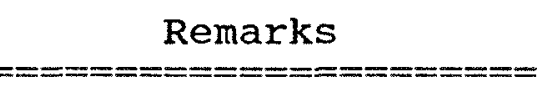 \\
\hline 1. Intro to course & none & lecture class outline \\
\hline $\begin{array}{l}\text { 2. Knowledge of cft } \\
\text { terminology }\end{array}$ & $\begin{array}{l}\text { overhead } \\
\text { projector } \\
\text { acetates } \\
\text { to display } \\
\text { terms }\end{array}$ & $\begin{array}{l}\text { Refer to Webster's on } \\
\text { terms and typologies } \\
\text { Discuss how to spot } \\
\text { various types of cft. } \\
\text { correctly identify } \\
\text { passing situations. } \\
\text { a. innocent pass/no } \\
\text { knowledge } \\
\text { b. deliberate passing }\end{array}$ \\
\hline 3. Intro to cft. & $\begin{array}{l}\text { Enlargements } \\
\text { of actual }\end{array}$ & $\begin{array}{l}\text { Point out flaws of } \\
\text { cft. \& (types of cft. } \\
\text { currency. Identity } \\
\text { keys of genuine } \\
\text { currency. }\end{array}$ \\
\hline
\end{tabular}

(Instructor should point to each key and explain how to identify counterfeit currency. Also the instructor should identify genuine currency in circulation and review questions from the posttest.) 
INSTRUCTORS GUIDE \& LESSON PLAN

Bank Teller Training

Lesson Plan \# 02

Ft. Lauderdale, Fla.

Page 2 of 3

Session: Identifying counterfeit Currency

objective: consistency in identifying and handling cft notes

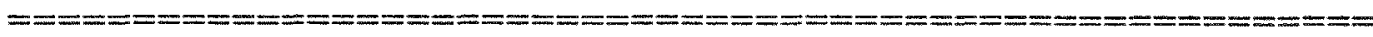

No. Subject Training Aid Remarks

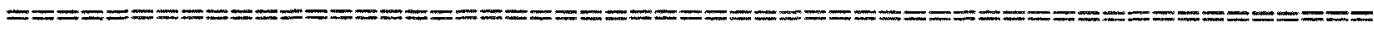

4. Features of

hand out

Genuine

of genuine and cft notes

students compare

quality currency

of both cft and

genuine notes.

(Instructor points out fibers appearing in genuine currency and the lack of

fibers in cft. money

Overhead projector (Instructor explains the various

processes the

counterfeiter uses i.e. offset presses, bleached notes, and cft made from plates

5. Bank policy and procedures

Instructor lectures on procedures and policy on detection of counterfeit money

(Mode of instruction is lecture with a visual review of types of counterfeit notes and the processes used for manufacture. Review genuine types of currency and identity keys tellers need to know.) 
INSTRUCTORS GUIDE \& LESSON PLAN

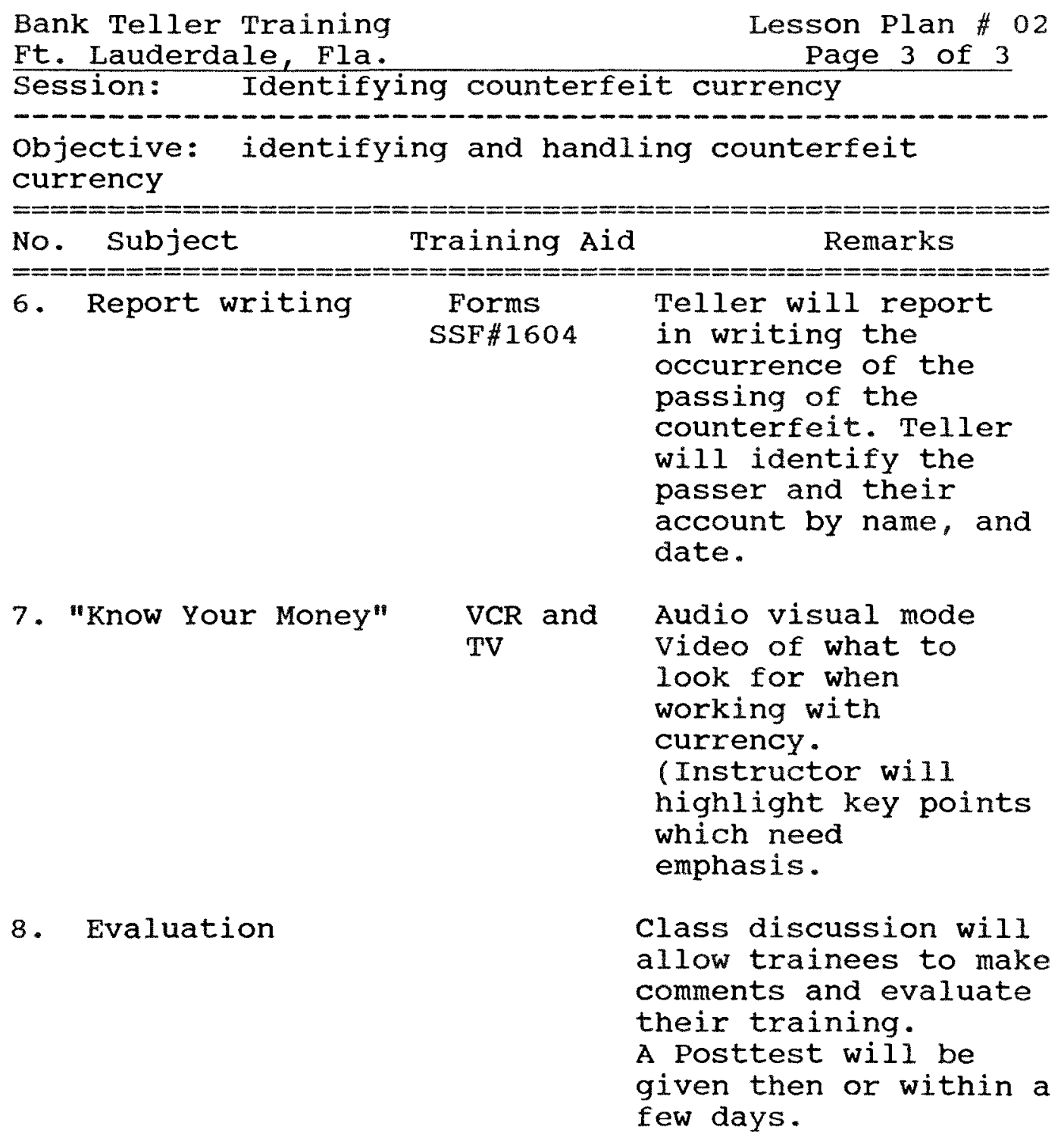


APPENDIX F

PARETO ANALYSIS OF NEED FOR TELLERS

TO LEARN TO DETECT COUNTERFEIT CURRENCY

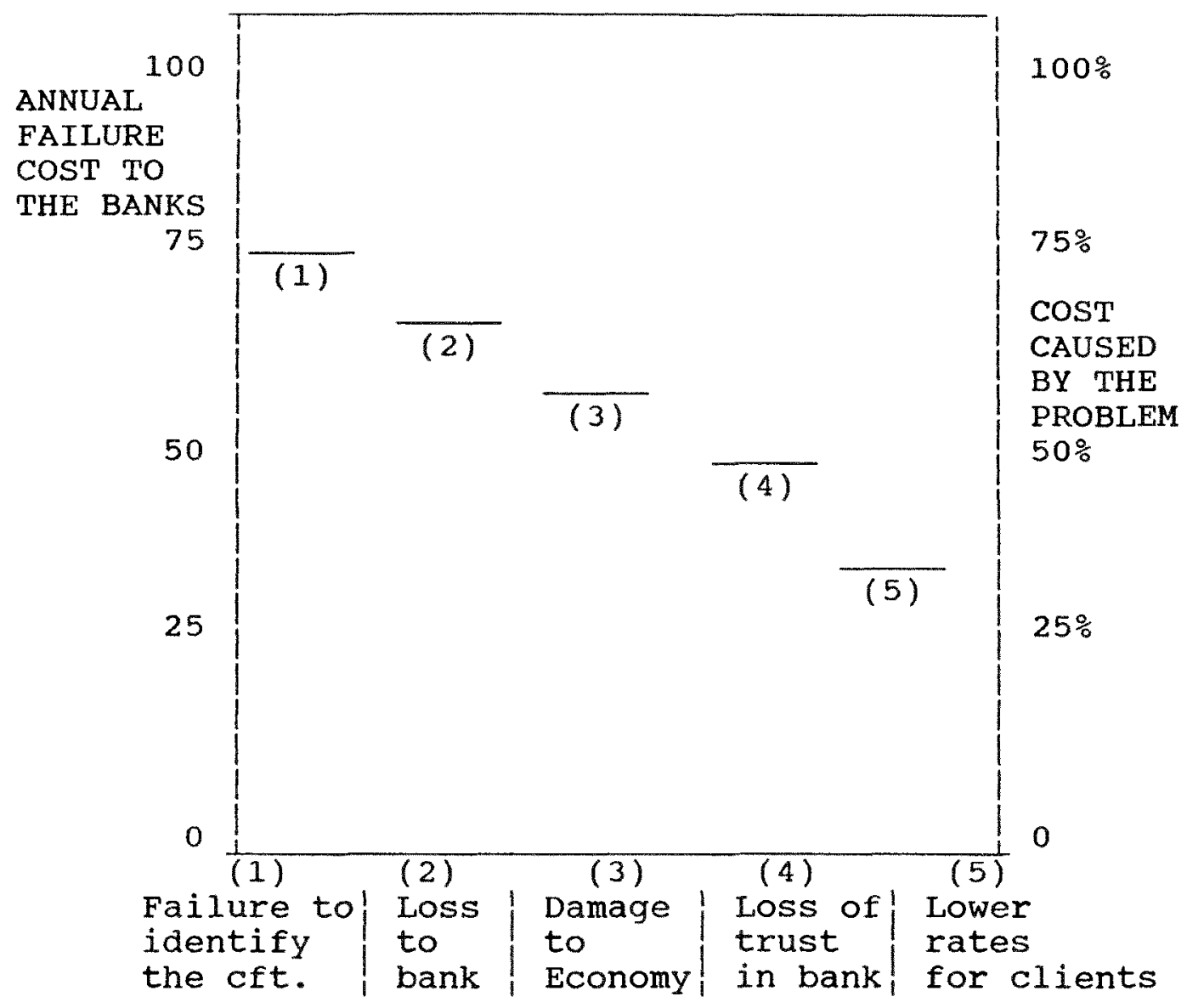




\begin{abstract}
APPENDIX G
LESSON PLAN \#1

CONTENT SPECIFIC LEARNING STRATEGY

Semantic only Encoding
\end{abstract}

I. Overview of Lesson (10 minutes approximate)

A. Introduction to class -

1. Definition of counterfeit (Webster's 1965)

2. What constitutes a genuine $U$. S. note

3. What constitutes a "counterfeit" note

4. Methods of detection of counterfeits.

B. Types of notes in circulation

c. Behavioral styles exhibited by passers of counterfeit.

D. Bank establishment procedures after detection of counterfeit

E. Video presentation on "Know Your Money."

II. Introduction to counterfeits (60 minutes approximate)

A. Questions from student's pretest on the detection of counterfeit currency.

1. Ask random tellers what they answered to select questions.

2. Go over correct answers for each of the questions.

B. Genuine currency- knowing what to look for in notes.

1. It is necessary for you to know more about what U. S. currency looks like.

a. check letter.

b. Federal Reserve Seal \& letter

c. portrait

d. serial number

e. quadrant number

f. back plate number

g. Treasury Seal

2. Types of genuine notes in circulation

a. Silver Certificates (blue)

b. United States Notes (Red)

c. Federal Reserve Notes (Green)

d. Gold certificates

(Gold) 
3. Special paper - printed under government regulation

a. red and blue fibers in paper

c. Passers of counterfeit and their behavior patterns

1. How to pass a counterfeit note. What the passer looks for in a teller.

2. Passing cft. scenario. (class activity)

3. What questions should the teller ask the passer.

* * * Break * * *

(10 minutes)

III. Lecture : Types of counterfeit - bank policy on cft. (30 min. approx.)

A. Types of counterfeits

1. "offset printing"

2. "bleached notes"

3. counterfeits from plates

B. Bank policy and procedures

1. Reporting to supervisory teller of incident

2. Whom to contact for verification

3. What forms need to be written up and reported

4. Which agency of the U. S. government needs to be contacted

to report the violation of law on a deliberate pass.

IV. Video Presentation on "Know Your Money"

(15 minutes)

* * * Break (10 minutes) * * *

v. Class discussion on Counterfeit Money (45 minutes) 
LESSON PLAN \#2

CONTENT SPECIFIC LEARNING STRATEGY

Visual and Semantic Encoding

Note: an $(*)$ appearing after the session

indicates a visual enhancement

I. Overview of the Lesson $(10$ minutes

approximate)

A. Introduction to class

1. Definition of counterfeit

(Webster's, 1965)

2. What constitutes a genuine U. S. note

3. What constitutes a "counterfeit" U.S. note

B. Types of notes in circulation

1. Distribute one of each of three types for inspection

2. What denominations are in circulation

c. Behavioral styles exhibited by passers of counterfeit

1. Point out photos of known passers and behavior

2. Demonstration of passers attempting to pass counterfeit

D. Banking Establishment's procedures for detected counterfeit currency

1. Demonstration

E. Video Presentation of "Know Your Money"

II. Introduction to Counterfeit Currency

(60 minutes approximate)

A. Questions from the Pretest on the detection of counterfeit currency are reviewed.

1. Randomly sample tellers on select questions from the pretest

2. Review all questions from the pretest and discuss their significance.

B. Genuine Currency-Knowing what to look for in currency.

1. It is necessary for you to know more about U. S. currency:

a. check letter 
b. Federal Reserve seal and letter

c. portrait

d. serial number

e. quadrant number

f. back plate number

g. U.S. Treasury seal

2. Types of notes in circulation

a. Silver certificate (Blue)

b. United States Note (Red)

c. Federal Reserve Note (Green)

d. Gold certificate (Gold)

3. Special paper - printed under U. S. government regulation in Massachusetts.

a. Red and blue fibers in paper (point out to class)

C. Exhibit blow ups of known counterfeits in front of the class

1. Point out defects on blow ups of counterfeits

2. Comparison to genuine note blow ups. *

D. Behavioral styles exhibited by passers of counterfeit currency

1. How to pass a counterfeit note. What the passer looks for in a teller.

2. What questions should the tellers ask the passer of cft. notes. 3. Class activity in passing of counterfeit
currency.

* * * Break - (10 minutes $) * * *$

III. Lecture: Types of counterfeit-Bank policy on cft notes ( $30 \mathrm{~min}$. approx.)

A. Types of Counterfeit Currency

1. pass out counterfeit currency to class

a) point out mistakes,

b) flaws and errors

2. offset printing

3. "bleached" notes

4. counterfeit from plates

5. get counterfeit notes returned.

B. Bank policy and procedures

1. Reporting to supervisory teller of incident with cft. 
2. Who to contact for verification

3. What forms need to be written up and reported

4. Which agency of the U.S. government needs to be contacted to report the violation of law on a cft. pass.

IV. Video presentation on "Know Your Money" (15 minutes)

* * * Break (10 minutes) * * *

V. Class Discussion on Counterfeit Currency (45 minutes approximate) 


\section{LESSON PLAN \#3}

CONTENT GENERAL LEARNING STRATEGIES

Semantic only Encoding

I. Overview of Lesson (10 minutes approximate)

A. Introduction to class

1. Methods of learning

a. Learning styles

b. Learning strategies

c. Learning techniques -

(e.g. problem solving)

2. How to apply styles and strategies to my individual use

a. How to I learn best

B. Why learn about counterfeit money?

1. What impact does this training have on my life?

2. Definition of counterfeit (Webster)

3. What constitutes genuine U. S. currency and why?

4. Why is a "counterfeit note" counterfeit?

5. Methods of detection: Could I learn this?

c. Types of notes in circulation

1. Have I seen any of these?

2. Could I recognize one of them if I saw it?

D. Behavioral styles exhibited by passers of counterfeit currency.

1. How to pass a cft. note. What the passer looks for in a teller.

2. Why is it important to learn about passers?

E. Bank policy and procedures relating to the detection of cft. notes

1. Can I learn the necessary procedures?

2. How do I relate to these policies?

F. Explanation of the video presentation "Know Your Money" 

II. Introduction to Learning Styles and Strategies

A. "Myers-Briggs Type Indicator" for learners 1. Introduction to the 16 Types of learners

2. Right Brain-Left Brain Integration style of learning

B. Do I fit into any of these models

1. How do I remember best?

2. Do I like to think on my own or do I prefer instruction?

3. How do I apply these rules to myself?

* * * BREAK * * *

(10 minutes)

III. Introduction to counterfeit currency

(55 minutes approximate)

A. Genuine currency-knowing what to look for in U. S. currency

1. Check letter

2. Federal Reserve seal and letter

3. Portrait

4. Serial number

5. Quadrant number

6. Back plate number

7. Treasury seal

8. Special paper

B. Types of notes in circulation

1. Silver Certificates (Blue - serial number and seal)

a. Denominations $-\$ 1, \$ 5$, and $\$ 10$. (no longer printed)

2. United States Notes (Red - serial number and seal)

a. Denominations $-\$ 2, \$ 5$, and $\$ 100$. (no longer printed)

3. Federal Reserve Note (Green - serial number and seal)

a. Denominations - $\$ 1, \$ 2, \$ 5, \$ 10, \$ 20, \$ 50$, and $\$ 100$.

4. The $\$ 100$ FRN is the highest denomination now being printed 
C. Types of counterfeits

1. Why is detecting counterfeit important to me?

2. Types of counterfeits

a. Offset printing

b. "Bleached notes"

c. Plate notes

d. Poor man's counterfeit

D. Passers of counterfeit currency and their behavioral patterns.

1. How to pass a counterfeit note. What the passer looks for in a teller.

2. What questions should the teller ask the presenter of a counterfeit note.

E. Bank policy and procedures relating to the detection of cft notes

1. Reporting to supervisory teller of incident

2. Who to contact for verification

3 . What forms need to be written up and reported

4. Which agency to contact to report passing incident

* * * BREAK * * * (10 minutes $)$

IV. Video presentation "Know Your Money"

v. Class Discussion on counterfeit money 


\section{LESSON PLAN \#4}

CONTENT GENERAL LEARNING STRATEGY

Visual and Semantic Encoding

I. Overview of the Lesson (10 minutes approximate)

A. Introduction to class

1. Methods of learning

a. Styles

b. Strategies

c. Techniques (e.g. - problem solving)

2. How to apply methods of learning to individual use

a. How do I learn best?

3. Applying learning strategies to learning about counterfeit currency

B. What are counterfeits? (what they will be learning.)

1. Definitions

2. What constitutes genuine currency (Overheads)

3. Why are "counterfeit notes" counterfeit? (Overheads)

4. Methods of detection

c. Types of genuine notes in circulation

D. Behavioral styles exhibited by passers of counterfeit currency.

1. How to pass a cft. note. What the passer looks for in a teller.

2. Why is important to learn about passers.

E. Bank policy and procedures relating to the detection of cft. notes.

1. Can I learn the necessary procedures?

2. How do I relate to these policies?

F. Explanation of the video presentation

"Know Your Money." 
II. Introduction to learning styles and strategies

A. "Myers-Briggs Type Indicator" for learners

1. Introduction to the 16 types of learners (give to group)

2. Right brain-left brain integration style of learning

B. Do I fit into any of these models

1. How do I remember best?

2. Do I like to think on my own or do I prefer instruction?

3. How do I apply these rules to myself?

\section{* * $*$ BREAK * * * (10 minutes)}

III. Introduction to counterfeit currency

A. Genuine currency-knowing what to look for in U. S. currency. (Use of enlarged blowup of U. S. currency)

1. Check letter

2. Federal Reserve seal and letter

3. Portrait

4. Serial number

5. Quadrant number

6. Back plate number

7. Treasury seal

8. Special paper

B. Types of notes in circulation

1. Silver Certificates (Blue - serial number and seal)

a. Denominations - $\$ 1, \$ 5$, and $\$ 10$ (no longer printed)

b. Pass out to class a silver certificate

2. United States Notes (Red - serial number and seal)

a. Denominations $-\$ 2, \$ 5$, and $\$ 100$ (no longer printed)

b. Pass out to class a U. S. Note

3. Federal Reserve Notes (Green - serial number and seal)

a. Denominations - $\$ 1, \$ 2, \$ 5, \$ 10, \$ 20, \$ 50$ and $\$ 100$. 
b. Pass out to class genuine FRN's to inspect

c. The $\$ 100$ FRN is highest denomination note now printed

C. Passers of counterfeit currency and their behavioral styles

1. How to pass a counterfeit note. What the passer looks for in a teller

2. What questions should the teller ask the presenter of a counterfeit note.

3. Passing counterfeit note scenario. (problem solving exercise) *

4. Types of behaviors exhibited by passers of counterfeit

1. Nervous passer

2. The friendly talker passer

3. The rush hour passer - always in a hurry

D. Types of counterfeits

1. Offset printing

2. "Bleached notes"

3. Plate notes

4. Poor man's counterfeit

5. Pass out counterfeit for inspection

E. Bank policy and procedures relating to detection of cft. notes

1. Reporting passing of cft to supervisory teller

2. who to contact for verification of cft.

3. What forms need to be written up and reported

4. Which agency to contact to notify of passing incident

* * * BREAK * * *

(10 MINUTES)

VI. Video presentation "Know Your Money" (15 minutes)

VII. Class discussion and wrap up (30 minutes)

(*) after the statement indicates a visual aid. 


\author{
APPENDIX H \\ JOB DESCRIPTION \\ PAYING AND RECEIVING TELLER
}

(abbreviated version)

A. Responsibilities

1. Accepting and processing currency, coin and checks which depositors tender for credit to their demand or time deposit account (s).

2. Accepting and processing bond coupons, food stamps, Visa/MasterCard, and American Express merchant deposits for credit by the Bank charge card payments.

3. Cashing savings withdrawals for depositors.

4. Exchanging checks drawn on the bank or other banks for currency payable to an individual when:

a. $\operatorname{check}(\mathrm{s})$ are in proper order;

b. check(s) are presented by a customer or person properly identified and known to the bank as having the right title and interest in the check ( $s)$;

c. check(s) are within teller check cashing limits

B. Human Relations Skills

1. Contact with customers - teller should smile, use the customer's name, greet the customer, be aware of the proper time to cross-sell a bank service, and close the transaction pleasantly, thanking the customer for their business.

2. Contact within the department - teller should treat co-workers with the same consideration and respect they would like to receive.

3. Contact with other departments - teller should display the same consideration and respect to co-workers in other departments.

4. Supervision given - teller may provide guidance to an assigned teller trainee for a 
specified period of time.

5. Supervision received - teller works under

direct supervision according to policies and procedures set by senior management. Teller should refer exceptions to policy and procedure to their supervisor for approval.

C. Job Duties

1. Prior to opening for business:

a. Turning on the teller machine and checking to be sure it registers the correct date and machine number;

b. Setting date stamp(s) with current date, when applicable;

c. Seeing that a sufficient supply of forms are available to handle the day's transactions

d. Removing currency and coin from the assigned compartment in the vault and placing it in the station compartment, being certain currency and coin, in sufficient denominations and quantity, are available to handle the current day's business.

2. Transacting the day's business:

a. Verifying, by counting, the amount of currency and coin tendered in a deposit;

b. Reviewing checks tendered for deposit to be certain they meet the requirements of negotiability, that is:

1. The instrument is drawn on a bank;

2. The check is signed;

3. Date on the check(s) is current (not post-dated or stale-dated);

4. The check bears no alteration or change in date, amount, name of payee, or signature;

5. The written and numerical amounts agree; 
6. Check is endorsed as written by the person to whom the item is payable and/or the person who is tendering the check for deposit. Checks made payable to a corporation, association, company, or several people jointly should not be accepted for deposit into an individual account without proper authorization and approval.

c. Receipting the total amount deposited by issuing a machine validated receipt to the depositor.

1. If it becomes necessary to correct a deposit slip because of an error, the teller should courteously ask the customer to correct the slip and initial the correction or ask the customer to fill out a new deposit siip.

2. If a customer tenders a check but only wishes to deposit part of the check and receive the difference in cash, the teller should note this transaction on the deposit slip as a "Split Deposit."

d. Accepting checks drawn on this bank tendered for exchange into currency and coin provided:

1. The endorser is known or properly identified (identification should be written on the back of the check);

2. The check is signed with an authorized and genuine signature;

3. It bears a current date (not post-dated or stale-dated);

4. It bears no alteration or change in date, amount, name of payee, or signature;

5. The amount as written agrees with the amount as printed;

6. It is endorsed by the person to whom the check is made payable 
and/or the person who is tendering the check for encashment.

7. There is a sufficient amount available in the account against which it is drawn to cover the amount of the check;

8. There is no stop payment order against the check.

e. Accepting checks drawn on other banks tendered for exchange into currency and coin provided;

1. The check is presented by a customer or properly identified person, known to be responsible for the amount of the check in case payment is refused by the bank on which the check is drawn;

2. The check is signed;

3. It bears a current date (not post-dated or stale-dated);

4. It bears no alteration or change in date, amount, name of payee, or signature;

5. The amount as printed agrees with the amount as written;

6. It is endorsed by the person to whom the check is payable and/or the person who is tendering the check for encashment.

3. Daily Balancing:

a. Counting and packaging all currency and coin on hand and entering respective amounts on the daily cash balance envelope;

b. Extract machine totals in the categories of cash-in and cash-out, and entering respective amounts on the teller envelope:

c. Other currency transactions such as cash transfers to or from the vault and/or other tellers should be appropriately listed;

d. Each column should be listed and totals MUST agree. 
4. Upon completion of Balancing:
a. Clearing and turning of machine;
b. Cleaning up the counter:
c. ordering necessary supplies for conducting the next day's transactions.

D. Job Specifications

1. Education/Experience
a. High School Diploma or GED;
b. One (1) year of money handling or cashiering experience;
c. Six (6) months to one (1) year of general bank experience.

2. Training - Successful completion of Teller Classroom Training; Successful completion of on-the-job training under sponsor/supervisor.

3. Skills - Abilities to operate NCR 279 Teller Machine, microfiche machine, and CRT.

4. Personal Appearance - Project a Professional Image.

5. Communication Skills - Must have good verbal communication skills in English for successful public contact. 


\begin{abstract}
APPENDIX I
Sample Letters to Banks and Savings and Loans

College of Education,

Florida International University

University Park Campus, DM 216

Miami, Florida 33117

May 27, 1989
\end{abstract}

Savings and Loan, Inc.

101 Somewhere st. ,

Miami, Florida 33132

ATTENTION: V.P. Training and operations

Dear Mr. - - - - ,

In response to our most recent discussions regarding teller training in the detection of counterfeit currency, I am forwarding a copy of a lesson plan to you. Please go over this outline with your training personnel, and if they have any questions have them contact me at 1234567 .

The training we discussed is part of a study I am conducting toward my Doctorate degree in Adult Education and Human Resource Development. The study will look at the degree of transfer of training between related and less related tasks, which bank tellers face in the detection of counterfeit currency and forged government checks.

It will be necessary for your trainers to administer a pretest several days prior to the training sessions and two different posttests after the training has been completed. Demographic information will be needed from each of the participating tellers.

Thank you for your assistance in this matter and again if I can be of any assistance to you please contact me.

Sincerely,

Ronald W. Collins 
College of Education,

Florida International University University Park Campus, DM 216 Miami, Florida 33117

April 7, 1989

Regular Banking Establishment

100 Anywhere street

Ft. Lauderdale, Florida 33301

ATTENTION: Senior Vice President operations and Training

Dear V.P. - - - ,

I am forwarding this letter per our conversation of this date regarding the training of tellers at your banking establishment for the purpose of detection of counterfeit money, forged government checks and altered U.S. genuine currency. I am presently engaged in doctoral studies at Florida International University and I am interested in studying the effects of transfer of training in a corporate setting. I find that training tellers would be ideal for this study.

The corporation would benefit from free training in the detection of counterfeit currency and forged government checks. I have had no little experience in this matter as I am presently a U. S. Secret Service agent with over eighteen years experience. Your corporation would also benefit in a secondary manner by being able to adjust training procedures for other types of teller tasks. An additional secondary benefit would come from the demographic breakdown needed to evaluate the study. An analysis of the demographic data of the tellers in your organization will enable you to see what type of personnel qualifications are most beneficial toward rapid learning of tasks and adjustment to organizational structure.

Thank you for any consideration that you give to this project.

Sincerely yours,

Ronald $w$. Collins 
REFERENCES

Anderson, R. and Ausubel, D. (Ed.) (1965). Readings in the psychology of cognition. New York, N.Y.: Holt, Rinehart \& Winston, Inc.

Block, N. (1981). Imagery. Cambridge, Mass.: The MIT Press.

Bloom, B. S.; Engelhart M. D.; Furst, E. J.; and Krathwohl, N. R. (1956) Taxonomy of educational objectives: Handbook I cognitive domain. New York: David McKay Co.

Briggs, L. J. and Wager, W. W. (1981). Handbook of procedures for the design of instruction. Englewood Cliffs, N. J.: Educational Technology Publications.

Brookfield, S. D. (1986). Understanding and facilitating adult learning. San Francisco, Ca.: Jossey Bass Publishers.

Bruner, J. S. (1960). The process of education. Cambridge, Mass: The Harvard University Press.

Bugelski, B. R., Kidd, E., and Segmen, J. (1968). Image as a mediator in one-trial paired associate learning. Journal of Experimental Psychology, 76, $69-73$.

Campione, J. C. and Brown, A. L. (1977). Memory and metamemory development in educable retarded children. In R. V. Kail, Jr. and J. W. Hagan (Eds.) Perspectives on the development of memory and cognition. Hillsdale, N.J.: Lawrence Erlbaum Assoc.

Chen, C. S. (1984, Dec.-Jan.). The importance of transfer training in elementary physics. Journal of College Science Teaching, 13, (Number) 3, 160-162.

Clements, D. H. (1984, October). Training effects on the development and generalization of piagetian logical operations and knowledge of number. Journal of Educational Psychology, 76, (Number) 5, pp. 766-777.

Cohen, J. (1977). Statistical power analysis for the behavioral sciences. New York, N.Y.: Academic Press. 
Conrad, C. (1978). Some factors involved in the recognition of words. In J.W. Cotton and R. L. Klatzky (Eds.) Semantic factors in cognition. New York: John wiley and Sons.

Cotton, J. W. and Klatzky, R. L. (Eds.) (1978). Semantic factors in cognition. New York: John Wiley and Sons.

Coxe, W. W. Jr. (1924). The influence of latin in the speliing of English words. Journal of Educational Research, 9, 223-233.

Craig, R. C. (1953). The transfer value of guided learning. New York: Teachers College, Columbia, University.

Craig, R. C. (1956). Directed versus independent discovery of established relations. Journal of Educational Psychology. 47, 223-234.

Craig, R. C. (1966). The psychology of learning in the classroom. New York: MacMillan Company.

Dansereau, D. (1978). The development of a learning strategies curriculum. In $\mathrm{H}$. F. O'Neil (Ed.) Learning Strategies. New York: Academic Press.

Dansereau, D. (1983). Learning strategy research. In J. Segal, S. Chipman, and R. Glaser (Eds.), Thinking and learning skills: relating instruction to basic research., Vol I., Hillsdale, N. J.: Erlbaum.

DeBono, E. (1967). New think: the use of latent thinking in the generation of new ideas. New York: Basic Books.

Dick, W. \& Carey, L. (1985). The systematic design of instruction. (2nd ed.). Glenview, Ill: Scott, Foresman.

Duncan, C. P. (1958). Transfer after training with single versus multiple tasks. Journal of Experimental Psychology, 55, 63-72.

Ellis, H. C. (1965). Transfer of learning. New York: MacMillan.

Ellis, H. C. (1972) Fundamentals of human learning, memory and cognition. Dubuque, Iowa: W. C. Brown. 
Ehrenberg, L. M. (1983, February). How to ensure better transfer of learning. Training and Development Journal, $2,81-83$.

English, H. B. and English, A. C. (1958). A comprehensive dictionary of psychological and psychoanalytic terms. New York: Longmans Green and Co.

Flavel1, J. H. (1981). Cognitive monitoring. In P. Dickson (Ed.) Children's oral communication skills, New York: Academic Press.

Gagne', R. M. (1974). Educational technology and the learning process. Educational Researcher, 3, 3-8.

Gagne', R. M. and Briggs, L. (1979). Principles of instructional design. New York: Holt, Rinehart and winston.

Gagne', R. M., Briggs, L. J., \& Wager, W. W. (1988). Principles of instructional design. (3rd ed.). New York: Holt Rinehart \& Winston, Inc.

Gay, L. R. (1987). Educational research, competencies for analysis and application. ( 3 rd Ed.) Columbus: Merrill Publishing co.

Gibson, J. J. (1966). The senses considered as perceptual systems. Boston: Houghton Mifflin.

Goldstein, K. M. and Blackman, S. (1978). Cognitive style, five approaches and relevant research. New York: John Wiley and Sons.

Haslerud, G. M. (1972). Transfer, memory and creativity; after learning and perceptual process. Minneapolis: University of Minn. Press.

Hooper, F. H. (1979, June). The efficacy of small group instructional activities for training piagetian concrete operations concepts. Journal of Genetic Psychology, 134, (Number) 2, 281-298.

Hopkins, K. D. and Glass, G. V. (1978). Basic statistics for the behavioral sciences. Englewood Cliffs, N. J.: Prentice Hall, Inc.

Hull, C. L. (1937). Mind, mechanism, and adaptive behavior. Psychological Review, 44, 1-32. 
Hunt, E. (1978). Imageful thought. In J.W. Cotton and R. L. Klatzky (Eds.) Semantic factors in cognition. New York: John Wiley and Sons.

Judd, C. H. (1908). The relations of special training to general intelligence. Education Review, 36, 28-42.

Judd, C. H. (1932). Autobiography. In Carl Murchison (Ed.) History of psychology in autobiography. Vol II. Worcester, Mass.: Clark University Press.

Kersh, B. Y. (1962). The motivating effect of learning by directed discovery. Journal of Educational Psychology, 53, 65-71.

Kerlinger, F. N. (1986). Foundations of behavioral research. New York, N.Y.: Holt Rinehart and Winston.

Klatzky, R. L. and Stoy, A. M. (1978). Semantic information and visual information processing. In $\mathrm{J}$. W. cotton and R. L. Klatzky (Eds.) semantic factors in cognition. New York: John Wiley and Sons.

Kosslyn, S. M. (1980). Image and mind. Cambridge, Mass: Harvard University Press.

Kosslyn, S. M. (1985). Mental imagery ability. In R. J. Sternberg (Ed.) Human abilities: an information processing approach. New York: W. H. Freeman and Co.

Lee, S. S. (1985). Children's acquisition of conditional logic structure: teachable? Contemporary Educational Psychology, 10, (Number) 1, 14-27.

Logan, G. D. and Zbrodoff, N. J. (1982). Constraints on strategy construction in a speeded discrimination task. Journal of Experimental Psychology: Human Perception and Performance, 8, 502-520.

Mackay, D. G. (1982, september). The problem of flexibility, fluency, and speed-accuracy, trade-off in skilled behavior. Psychological Review, 89, (Number) 5, 483-506.

Mager, R. (1962). Preparing instructional objectives. Belmont, Ca.: Fearon Publishers. 
McCormick, E. J. (1979). Job analysis: methods and applications. New York: Amacom.

Neisser, U. (1967). Cognitive psychology. New York: Appleton-Century-Crofts.

Prather, D. C. (1971). Trial and error versus errorless learning: training, transfer, and stress. American Journal of Psychology, 84, 377-386.

Rapp, A. (1945, May). Experimental background of the problem of learning. Classical Journal, 40, 467-480.

Rogoff, B. and Gauvain, M. (1984, December). The cognitive consequences of specific experiences: Weaving versus schooling among the navajo. Journal of cross-Cultural Psychology, 15, (Number) 4, 453-475.

Rohwer, W. D.,Jr. (1966). Constraints, syntax and meaning in paired-associate learning. Journal of Verbal Learning and Verbal Behavior, 5, 541-547.

Rumelhart, D. E. and Norman, D. A. (1978) Accretion, tuning and restructuring: three modes of learning. In J. W. Cotton and R. L. Klatzky (Eds.) Semantic Factors in Cognition. New York: John Wiley and Sons.

Singer, R. J. (1978). Motor skills and learning strategies. In $\mathrm{H}$. F. O'Neil (Ed.) Learning strategies. New York: Academic Press.

Singer, R. J. and Cauraugh, J. H. (1984). Generalization of psychomotor learning strategies to related psychomotor tasks. Human Learning, 3, 215-225.

Singer, R. J. and Cauraugh, J.H. (1985). The generalizability effect of learning strategies for categories of psychomotor skills. Quest, 37, 103-119.

Singer, R. N. and Pease, D. (1976). A comparison of discovery learning and guided instructional strategies on motor skill learning, retention, and transfer. Research Quarterly, 47, (Number) 4, 788-795. 
Singer, R. N. and Suwanthada, S. (1986). The generalizability effectiveness of a learning strategy on achievement in related closed motor skills.

Research Quarterly for Exercise and Sport, 57, (Number) $3,204-214$.

Skinner, B. F.(1968). The technology of teaching. New York: Appleton.

Sless, D. (1981). Learning and visual communication. New York: John Wiley \& Sons.

Sternberg, R. J. (1985). Human abilities: An information processing approach. New York: W. H. Freeman \& Co.

Szuchman, L. T. (1987). Qualitative changes in verbal abilities across the adult years. Unpublished Master Thesis, Florida International University.

Thorndike, E. L. (1913). The psychology of learning. Vol II. New York: Teachers College, Columbia University.

Thorndike, R. L. \& Hagen, E. (1986). Measurement and evaluation in psychology and education. (5th ed.) New York: Wiley.

Weaver, D. (1987, April). Transfer of learning not yet understood. Journal of Reading, 1, 582-583.

Weinstein, C. (1975). Learning elaboration strategies. Dissertation Abstracts International, Austin, Texas: University of Texas.

Weinstein, C. (1978). Elaboration skills as a learning strategy. In H. F. O'Neil (Ed.) Learning strategies. New York: Academic Press.

Weinstein, C. and Rogers, B. T. (1984). Comprehension monitoring: The neglected learning strategy. Journal of Developmental Education, 9, (Number) 1, 6-9.

Weinstein, C. (1987, April). Fostering learning autonomy through the use of learning strategies. Journal of Reading, 1, 590-595. 
VITA

Ronald William Collins was born in New York City, N. Y. on January 6, 1947, the son of Captain Edward H. Collins, Ir., U. S. Army and Estelle L. Collins. He was graduated from Parsippany High School in New Jersey in 1965. He was graduated from Rutgers University in New Jersey with a major in History in 1969. During 1969-1970 he studied History at Hunter college's School of Graduate study at the city University of New York.

In May 1987 he received the Master of Science degree in Counseling Psychology from Nova University. Also in May 1987 he entered the doctoral program in Adult Education and Human Resource Development at Florida International University in Miami.

From 1970 through 1990 he worked for the Treasury Department in an investigative capacity, as special Agent of the U. S. Secret service. He is an expert in the detection of counterfeit currency and in the field of executive security. He anticipates retirement from government service in the summer of 1991.

Upon retirement from government service he plans to enter the academic field and seek an instructional position in an institution of higher learning. He is interested in educational research, writing, and corporate consulting. 
He has published a novel, several technical reports, and an article in a business research journal. Future writing plans include a textbook in the field of human resource development. He currently resides in Ft. Lauderdale, Florida. 